\title{
LA OTRA CARA DE LA REFORMA DEL CONSEJO DE SEGURIDAD. SUS MÉTODOS DE TRABAJO
}

\author{
Eva María RUBio FERNÁNDEZ*
}

RESumen: En el vigente proceso de reforma del Consejo de Seguridad, en el seno del Grupo de Trabajo de la Asamblea General se ha puesto reiteradamente de relieve la importancia que tiene la mejora de los métodos de trabajo en la consecución de un órgano legítimo y eficaz. En los últimos periodos de sesiones, esta otra dimensión de la reforma del Consejo ha cobrado protagonismo y continuado su estela de resultados. Este artículo analiza estos últimos desarrollos de cara a las futuras evoluciones de este proceso.

ABSTRACT: In the present process of the Security Council's reform, the Open-Ended Working Group of the General Assembly emphasized repeatedly the relevance that has the improvement of its working methods in the attainment of a legitimate and effective organ has. In the United Nations General Assembly's recent sessions, this cluster of the cited reform has gained acknowledgement and credits as well as increased its results. This paper analyzes the latter developments with a view to the future evolutions of this process.

RÉSUMÉ: Dans le cadre du processus de la réforme du Conseil de Sécurité, le Groupe de travail à composition non limitée de l'Assemblée Générale a réitérativement mis en relief l'importance de l'amélioration des méthodes de travail afin de le rendre plus légitime et efficace. Dans les dernières sessions de l'Assemblée Générale, ce groupe II de questions de la réforme du Conseil a gagné reconnaissance et notoriété aussi que il a augmenté les résultats obtenus. Cet article analyse ces derniers développements vis-à-vis des évolutions futures de ce processus.

* Profesora ayudante y doctora en derecho internacional público y relaciones internacionales en la Universidad de Murcia. 
SUMARIO: I. Consideraciones generales. II. La posición de las cuestiones conexas en el proceso de reforma. III. Proposiciones recientes, prácticas y maneras de entender el Consejo de Seguridad. IV. Consideraciones finales.

\section{CONSIDERACIONES GENERALES}

La introducción de borradores de resolución alrededor del vigente proceso de reforma del Consejo de Seguridad no se ha producido hasta fecha relativamente reciente, lo cual aún suponiendo una variación respecto al entonces normal discurrir de los trabajos, no ha provocado la inflexión en el ralentizado proceso, no al menos de forma inmediata.

Así, en un primer momento, las reacciones provocadas por los borradores de resolución presentados por el Grupo de los 4, el Grupo Unidos por el Consenso y el Grupo Africano, en lugar de derivar en un impulso hacia la negociación y terminación del proceso, lo hicieron hacia una situación extremadamente similar a aquélla que, en su momento, condujo a la adopción de la Resolución 53/30, de 23 de noviembre de $1998,{ }^{1}$ haciendo temer no sólo que el impulso de la Cumbre Mundial 2005 se perdiese, respecto de la reforma del órgano restringido, sino también que el mismo volviese a entrar en una fase de mera reiteración de propuestas y anquilosamiento extremo de las posturas. Pasada la reunión de Alto Nivel, donde se solicitó el examen de la evolución de la reforma del Consejo del Seguridad, la cual apoyaban plenamente, a finales de $2005,{ }^{2}$ y con una Presidencia de la Asamblea General nada dispuesta a que la cuestión de la reforma del Consejo de Seguridad pudiese estar en el origen de un solo revés en el resto del proceso de mejora de la Organización, los vicepresidentes de turno del Grupo de Trabajo de composición plenaria de la Asamblea General sobre la representación equitativa del Consejo de Seguridad y el aumento de sus miembros y otras cuestiones conexas (en adelante, Grupo de Trabajo de la Asamblea General), ${ }^{3}$ obtuvieron la con-

1 Sobre esta situación y su parecido con la habida en el quincuagésimo tercer periodo de sesiones, véase mi trabajo "Sombras y luces en las dos dimensiones de la reforma del Consejo de Seguridad”, en Beneyto, José María (dir.), Una nueva organización de Naciones Unidas para el siglo XXI, Madrid, Biblioteca Nueva, en prensa.

2 A/RES/60/1 del 16 de septiembre de 2005, parágrafo 153.

3 La Resolución 48/26 del 3 de diciembre de 1993, estableció este Grupo de Trabajo como el mecanismo de preparación de esta reforma. 
firmación de que el proceso de reforma seguía contando con el apoyo de las delegaciones gubernamentales que mantenían su posición de considerarlo parte fundamental e ineludible del proceso general de reforma de la Organización. ${ }^{4}$

Tras ello, el proceso parece asistir a un nuevo impulso gracias al firme compromiso de la actual presidenta del órgano plenario, Sheikha Haya Rashed Al Khalifa (Bahrein), y sus facilitadores, resueltos todos ellos a recordar a los Estados miembros su compromiso con el objetivo de la reforma del Consejo de Seguridad y la necesidad de adoptar posiciones flexibles para alcanzarlo. ${ }^{5}$ Tanto es así que los facilitadores ante la existencia de visos de flexibilidad en las posturas hasta ahora impertérritas y la insistencia en la negación de la compresión del Grupo de Trabajo de la Asamblea General como foro de negociación, ${ }^{6}$ han recomendado que, en el marco oportuno, las negociaciones gubernamentales deberían

4 Ibidem, p. 8. Esta confirmación fue obtenida a través de una fórmula de reuniones bilaterales muy parecida a las conocidas como "reuniones de confesionario", mantenidas a partir del 26 de enero de 2006, con "no menos de 58 delegaciones" (Informe del Grupo de Trabajo de Composición Abierta sobre la Cuestión de la Representación Equitativa en el Consejo de Seguridad y del Aumento de sus Miembros y otros Asuntos relativos al Consejo de Seguridad, Doc. A/60/47, aprobado y distribuido el once de septiembre de 2006, anexo I, p. 5). Sobre las reuniones de confesionario, véase mi trabajo El Consejo de Seguridad de Naciones Unidas. A la búsqueda de la legitimidad y de la eficacia, Valencia, Tirant lo blanch, en prensa.

5 Véase, en este sentido, el Informe de los Facilitadores a la Presidenta de la Asamblea General sobre las Consultas relativas a la "Cuestión de la representación equitativa en el Consejo de Seguridad y del aumento del número de sus miembros y otras cuestiones relacionadas con el Consejo de Seguridad" (en adelante, Informe de los Facilitadores) del 19 de abril de 2007, y la Carta de la Presidenta de la Asamblea General a todos los Representantes Permanentes y Observadores Permanentes de las Naciones Unidas (Nueva York) sobre las Consultas relativas a la Reforma del Consejo de Seguridad del 22 de mayo de 2007, ambos disponibles en http://www.un.org/ga/president/61/follow-up/securitycouncilreform.shtml. Los cinco facilitadores nombrados por la presidenta fueron los embajadores y representantes permanentes Heraldo Muñoz (Chile), Andreas D. Mavroyiannis (Chipre), Mirjana Mladineo (Croacia), Frank Majoor (Holanda) y Ali Hachani (Túnez) (Discurso ante el Grupo de Trabajo de la Asamblea General del 8 de febrero de 2007, disponible en http://www.un.org/ga/president/61/statements/statement20070208. shtml.

6 Informe de los Facilitadores, parágrafos 2 y 3 , y 8 y 9, pp. 4 y 5. 
comenzar. ${ }^{7}$ Idea ésta última que ya estuvo presente en el espíritu de anteriores presidentes del Grupo de Trabajo y correspondientes vicepresidentes, y fue defendida en numerosas ocasiones por los candidatos a miembros permanentes, pero que, a diferencia del enfrentamiento y parálisis que hasta ahora parece haber comportado su invocación, en esta ocasión podría generar alentadoras evoluciones. ${ }^{8}$

\section{LA POSICIÓN DE LAS CUESTIONES CONEXAS EN EL PROCESO DE REFORMA}

Entre todos los borradores presentados a lo largo del quincuagésimo noveno y sexagésimo periodo de sesiones, hubo uno que supuso una especial novedad. El 20 de marzo de 2006, por primera vez de forma oficial, se hacía circular un proyecto de resolución que versaba exclusivamente sobre la mejora de los métodos de trabajo del Consejo de Seguridad. ${ }^{9}$ Sus patrocinadores, Costa Rica, Jordania, Liechtenstein, Singapur y Suiza, bautizados como los Small 5, habían hecho circular unos meses antes de forma oficiosa prácticamente el mismo texto en aras de generar un intercambio constructivo de opiniones y sopesar si correspondía dar un paso adelante, como así efectivamente ocurrió. De este modo,

7 "Los facilitadores consideran que ya se ha abierto un camino por el cual los Estados miembros podrían avanzar hacia negociaciones significativas, aprovechando la situación favorable que existe en este momento". Ibidem, p. 8.

8 La actual presidenta, de acuerdo con su intención de guiar el proceso desde la perspectiva de la obtención de resultados, encargó a los embajadores y representantes permanentes Heraldo Muñoz (Chile), y Christian Wenaweser (Liechtenstein), la función de celebrar consultas sobre el modo de hacer avanzar el proceso de reforma e informarle antes del final de junio (Carta de la Presidenta de la Asamblea General a todos los Representantes Permanentes y Observadores Permanentes de las Naciones Unidas (Nueva York) del 22 de mayo de 2007). El informe era presentado y distribuido el 26 de junio de 2007 y en su apartado V, dedicado a las "Medidas futuras", el lenguaje utilizado invocó en numerosas ocasiones a las negociaciones como siguiente paso en la evolución del proceso (véase Informe a la Presidenta de la Asamblea General sobre las Consultas relativas a "La cuestión de la representación equitativa en el Consejo de Seguridad y el aumento del número de sus miembros y otros asuntos relativos al Consejo de Seguridad del 26 de junio de 2007, parágrafos 25-30). El futuro de estas recomendaciones, cabe esperar, se decidirá en la reunión del Grupo de Trabajo a ser mantenida el 19 de julio de 2007. Todos los textos están disponibles en http://www.un.org/ga/president/61/follow-up/security councilreform.shtml.

9 Doc. A/60/L.49 del 17 de marzo de 2006. 
se venía a resaltar una de las características del vigente proceso de reforma del Consejo de Seguridad: la inclusión en su alcance de la mejora de sus métodos de trabajo y procedimiento.

Estas cuestiones, sistematizadas como grupo de materias II (cluster II) en el programa del Grupo de Trabajo de la Asamblea General, en puridad comprenderían las relacionadas con su sistema de votación y, más concretamente, con el derecho de veto, pero que se vieron privadas de éstas al decidirse que las mismas serían tratadas con las proposiciones de modificación de su composición. Decisión que, sin embargo, ha abandonado sus perfiles más estrictos en los últimos periodos de sesiones. ${ }^{10}$

Esa circunstancia contribuyó a que los avances y debates sobre las propuestas relacionadas con el funcionamiento del Consejo de Seguridad quedasen en una cierta penumbra. Penumbra más externa y formal que interna y material ya que la técnica conocida como package deal ${ }^{11}$ garantizó que los métodos de trabajo del Consejo de Seguridad no sufrieran las consecuencias de las excluyentes pasiones despertadas por los temas de composición y ampliación de la titularidad del derecho de veto y recibiesen las mismas dosis de atención y tratamiento por parte de las delegaciones gubernamentales. Una técnica que, por otra parte, también ha conseguido frenar el impulso de las escasas voces que han abogado por un tratamiento separado a favor de las propuestas relativas a los métodos de trabajo, a resultas del borrador de resolución del S5. ${ }^{12}$

10 Esta ubicación dejó de ser tan clara en el 59o. periodo de sesiones, ya que algunas delegaciones gubernamentales reivindicaron su pertenencia al grupo de materias II y la necesidad de abordar su tratamiento junto a las demás cuestiones de este grupo (Informe del Grupo de Trabajo de Composición Abierta sobre la Cuestión de la Representación Equitativa en el Consejo de Seguridad y del Aumento de sus Miembros y otros Asuntos relativos al Consejo de Seguridad, Doc. A/59/47, aprobado el 1o. de septiembre de 2005 y distribuido el 9 del mismo mes, anexo II, parágrafo 20, p. 11). En el periodo siguiente, sin embargo, su tratamiento osciló entre el grupo de materias II y la independencia (Doc. A/60/47, anexo I, p. 6, y anexo II, p. 10), para regresar a la ubicación inicialmente decidida en el 61o. periodo de sesiones (Informe de los Facilitadores, pp. 10-13).

11 Fue adoptada, por primera vez, en 1997 (Doc. A/50/47/Rev.1 del 31 de enero de 1997, parágrafo 17, p. 6). Sobre su uso, véase Winkelmann, Ingo, "Bringing the Security Council into a New Era: Recent Developments in the Discussion on the Reform of the Security Council", Max Planck Yearbook of United Nations Law, 1997, p. 88.

12 De hecho, el único resultado obtenido por estos intentos ha sido el que esta técnica haya recibido redacciones diferentes a la habitual (véase Doc. A/59/47, anexo II, parágrafo 2 in fine, p. 6, Doc. A/60/47, anexo I, p. 6, e Informe de los Facilitadores a la Presidenta de la Asamblea General sobre las Consultas relativas a la "Cuestión de la repre- 
Este anclaje de los avances del grupo de materias II a la suerte que corran los temas de composición y sistema de adopción de decisiones en el órgano restringido no debe ser minusvalorado, ya que no resulta osado afirmar que nos encontramos ante el aspecto esencial de esta reforma. ${ }^{13}$ Ello porque la mejora de estos métodos de trabajo contribuyen en mayor grado y concreción que las propuestas del grupo de materias I a la consecución del objetivo primero y último de este proceso, tal y como fue acordado al inicio de este proceso por los miembros del Grupo de Trabajo de la Asamblea General o, lo que es lo mismo, todos los de la Organización. Este objetivo no es otro que la vigencia de los principios de contribución al mantenimiento de la paz y seguridad internacionales y demás propósitos de la Carta, y de distribución geográfica equitativa y de igualdad soberana, así como la potenciación del carácter democrático, representativo, transparente, eficiente, legítimo y eficaz del Consejo de Seguridad, así como de su capacidad para rendir cuentas. ${ }^{14}$ Por ende, ha de tenerse en cuenta que su trascendencia se incrementará si se adicionan nuevos miembros a este órgano pues, al aumentar el riesgo de que los elegidos por la historia, la Asamblea General o, en su caso, los grupos regionales, sean los que exclusivamente marquen los designios de la Organización y de la comunidad internacional, sólo la existencia y despliegue de unos métodos de trabajo transparentes, inclusivos, democráticos, bien planteados y ejecutados, neutralizarán esa posibilidad ofreciendo la legitimidad y credibilidad necesarias para que la acción del Consejo sea eficaz. Más aún. En el poco hipotético supuesto de que no se lleve a cabo el

sentación equitativa en el Consejo de Seguridad y del aumento del número de sus miembros y otras cuestiones relacionadas con el Consejo de Seguridad" del 19 de abril de 2007, parágrafo 6, p. 5). En el debate mantenido el 20 de julio de 2006, uno de los temas principales a tratar fue precisamente si se negociaba la adopción del borrador de resolución presentado por el S5, o bien se mantenía el tratamiento paralelo, pero separado, primando como se ha expuesto esta segunda posición (Doc. A/60/PV.94 y Doc. A/60/PV.95 del 20 de julio de 2006, así como Doc. A/60/PV.96 del 21 de julio de 2006).

13 Abellán Honrubia así lo señalaba al resaltar como cuestiones básicas el funcionamiento, la transparencia, la participación en el proceso de los interesados o el sistema de adopción de decisiones. Véase Abellán Honrubia, Victoria, "La reforma de la Carta de las Naciones Unidas", en varios autores, La seguridad internacional, el derecho y los crímenes de guerra. IV Curso Internacional de Defensa, 16-20 de septiembre de 1996, Jaca, Academia General Militar de Zaragoza, Servicio de Publicaciones, 1997, p. 79.

14 Doc. A/49/47 del 8 de febrero de 1996, parágrafo 14, p. 4, y Doc. A/58/47 del 21 de julio de 2004, parágrafo 14, pp. 2 y 3 . 
incremento de sus miembros, hay que tener en cuenta que los métodos de trabajo son el engranaje que garantiza el funcionamiento de un órgano que, si bien no suele debatir parte de su agenda, ${ }^{15}$ no cesa de ver cómo su programa de trabajo se amplía vertiginosamente, entre otros motivos, por su tendencia creciente a la extralimitación competencial y la usurpación de funciones respecto de otros órganos principales, a través de la continua invocación del capítulo VII de la Carta.

Aumento de competencias que, de este modo, no sólo afecta a la relación interinstitucional dentro de las Naciones Unidas, sino también al propio funcionamiento del Consejo, lo que ha dado lugar a la solicitud de una mayor delegación de las funciones de los representantes permanentes en expertos, asesores políticos o coordinadores políticos, éstos últimos poseedores ya de un papel central en sus respectivas misiones nacionales ${ }^{16}$ o, incluso, de la mayor utilización y exploración de las posibilida-

15 En este sentido, se adoptaron una serie de medidas para aligerar la agenda del Consejo de Seguridad como la remoción de los asuntos no tratados durante un quinquenio con la posibilidad de mantenerlos un año más, tras el cual, si no habían sido debatidos, serían automáticamente eliminados de la agenda. A petición de la mayoría de miembros de Naciones Unidas, la remoción automática fue suprimida, quedando ésta a expensas del consentimiento de éstos (véase las notas del presidente del Consejo de Seguridad en documentos S/26812 del 29 de noviembre de 1993; S/1994/896 del 28 de julio; S/1996/55 del 24 de enero; S/1996/603 del 22 de agosto; y S/1996/704 del 29 de agosto). Ello ha generado que existan asuntos en la agenda que no han sido debatidos desde hace más de diez años (véase Doc. A/60/352 del 13 de septiembre de 2005, y Doc. A/54/398 del 20 de septiembre de 1999), como el relativo a las islas Tunb Mayor, Tunb Menor y Abu Musa en el que están implicados Irán y los Emiratos Árabes Unidos, mantenido en la agenda gracias a las peticiones de éste último (la más reciente se halla en Doc. S/2007/21 del 19 de enero).

16 Las sugerencias que apuntan a que en manos de los embajadores sólo queden las cuestiones claves y la planificación estratégica (alrededor del 15 o 20\% del trabajo del Consejo de Seguridad), al igual que las consideraciones que se plantearon alrededor del riesgo que conlleva depositar tanta responsabilidad en manos de los expertos, se encuentran en el informe final del curso práctico "Eficacia inmediata" para los miembros recién elegidos del Consejo de Seguridad, celebrado a finales de 2004, organizado por la delegación de Finlandia, en cooperación con el Center on International Organization de la Universidad de Columbia, la División de Asuntos del Consejo de Seguridad de la Secretaría de las Naciones Unidas y el Instituto de las Naciones Unidas para Formación Profesional e Investigaciones (UNITAR) (Doc. S/2005/228 del 6 de abril, pp. 10 y 11). Sobre la posición clave de los coordinadores políticos, véase los informes correspondientes a la primera edición de dicho curso, celebrada en 2003 (Doc. S/2004/135 del 20 de fe- 
des de los capítulos VI y VIII de la Carta $^{17}$ como vías de tratamiento y correspondiente aligeramiento de su programa de trabajo.

Por todo ello, cabe plantearse cuál ha sido el tratamiento que este grupo de materias ha recibido en las evoluciones recientes de este proceso. Así, si acudimos a los distintos borradores de resolución de los principales grupos de interés presentados de forma oficial, por primera vez en todo el proceso, ${ }^{18}$ reintroducidos dos de ellos durante el sexágesimo periodo de sesiones sin modificación alguna, comprobamos cómo, en términos generales, éste ha sido secundario e insuficiente, obviando la labor realizada en el Grupo de Trabajo de la Asamblea General. Así, la propuesta del Grupo Africano (cuya posición común más reciente es conocida como "Consenso de Ezulwini") hizo una referencia genérica, además de inadecuada, a esta mejora al contemplar en su parte dispositiva la decisión de la Asamblea General de mejorar los métodos de trabajo del Consejo de Seguridad, acción que sólo puede acordar éste último al ser el dueño de su procedimiento (artículo 30 de la Carta). ${ }^{19}$ Por su parte, la presentada por el Grupo Unidos para el Consenso, subrayando la urgente

brero, pp. 15 y 16) y a la cuarta, celebrada en 2006 (Doc. S/2007/137 del 12 de marzo, pp. 6 y 7$)$.

17 Véase por todos Doc. A/59/47, anexo II, parágrafos 8 in fine y 16, pp. 8 y 10, y Documento de trabajo no revisado de Suiza, recomendación 15. Recordatorio que, C. Fernández de Casadevante Romaní reclamaba, le debía haber sido hecho por la Corte Internacional de Justicia a raíz del asunto Lockerbie. Fernández de Casadevante Romaní, Carlos, Derecho internacional público, Madrid, Dilex, 2003, p. 217.

18 Imposible negar la influencia ejercida por el sexagésimo aniversario de Naciones Unidas, mediante el informe del Grupo de Alto Nivel sobre las amenazas, los desafíos y el cambio: Un Mundo más Seguro: la Responsabilidad que Compartimos (Doc. A/59/565 del 2 de diciembre de 2004); así como el del secretario general: Un Concepto más Amplio de la Libertad: Desarrollo, Seguridad y Derechos Humanos para Todos (Doc. A/59/2005 del 21 de marzo de 2005, principalmente de su parágrafo 170 in fine, p. 47).

19 Doc. A/59/L.67 del 14 de julio de 2005, y Doc. A/60/L.41 del 14 de diciembre de 2005, parágrafo a) in fine, en ambos. La Posición Común Africana sobre la Reforma de Naciones Unidas Propuesta o Consenso de Ezulwini, adoptada durante la 7a. sesión extraordinaria por el Consejo Ejecutivo de la Unión Africana, celebrada del 7 al 8 de marzo en Addis Abeba (Etiopía) en la Decisión sobre el Informe del Grupo de Alto Nivel sobre la Reforma de Naciones Unidas (Doc. Ext/Ex.CL/Dec.1 (VII), parágrafo 2), tampoco incluye mención específica a los métodos de trabajo del Consejo de Seguridad, como se comprueba en su texto (Doc. Ext/EX.CL/2 (VII) de igual fecha, pp. 9 y 10). Consenso que fue confirmado en la Decisión Assembly/AU/Dec.155 (VIII), adoptada en la 8a. sesión ordinaria de la Asamblea de la Unión Africana, celebrada del 29 al 30 de enero de 2007, en Addis Abeba (Etiopía). 
necesidad de perfeccionar los métodos de trabajo en su preámbulo, incluía cuatro proposiciones igualmente genéricas o sobre aspectos parciales, e instaba la finalización de la labor del Grupo de Trabajo de la Asamblea General y la celebración de consultas entre los Estados miembros para acordar nuevas disposiciones. ${ }^{20} \mathrm{~A}$ su vez, el borrador de resolución gestado en el seno del G4 o Alianza de los Cuatro ${ }^{21}$ incluía en su parágrafo final una serie de sugerencias concretas que, contando con el consenso en el Grupo de Trabajo de la Asamblea General, estaban extraídas del documento de trabajo que fue en su día presentado oficiosamente por el entonces presidente de la Asamblea General y a la sazón del Grupo de Trabajo, Razali Ismail. ${ }^{22}$

Dado el respaldo primigenio a este grupo de materias ${ }^{23}$ y el magnífico recibimiento que la mayoría de los Estados miembros otorgó tanto al documento de trabajo no revisado presentado por la delegación helvética, como al borrador de resolución elaborado por el Small 5 (Costa Rica, Jordania, Liechtenstein, Singapur y Suiza), ${ }^{24}$ ambos referidos exclusiva-

20 Doc. A/59/L.68 del 21 de julio de 2005, parágrafos 7-9.

21 Desde principios de 2006, el G4 (Alemania, Brasil, India y Japón) mantiene su denominación como tal, pero en la práctica cuenta con la ausencia formal de la delegación nipona que decidió continuar su camino hacia la permanencia solitaria, si bien manteniendo solidaridades con los tres restantes (véase sus evoluciones desde entonces en http://www.mofa.go.jp/policy/un/reform/index.html).

22 Doc. A/59/L.64 del 6 de julio de 2005, y Doc. A/60/L.46 del 6 de enero, parágrafo 8, de ambos. La propuesta de Razali Ismail, contenida en Doc. A/AC.247/1997/CRP.1 del 20 de marzo de 1997, disponible en Doc. A/51/47 del 8 de agosto de 1997, pp. 6-9, generó uno de los momentos de enfrentamiento más hirientes de todo el proceso, sólo seguido en dureza por el producido en la segunda mitad del 59o. periodo de sesiones, y culminó en la adopción de la Resolución 53/30 del 23 de noviembre de 1998, por la que cualquier decisión sobre la reforma del Consejo de Seguridad deberá ser adoptada por, al menos, dos tercios de los Estados miembros de Naciones Unidas.

23 De los ochenta y un Estados que respondieron al cuestionario enviado por el secretario general, en cumplimiento de la Resolución 47/62 del 11 de diciembre de 1992, cincuenta respaldaron la inclusión de estas cuestiones en este proceso. Cuando se produjeron los debates que antecedieron a la adopción de la Resolución 48/26, diecisiete Estados se sumaron a los anteriores.

24 El documento de trabajo no revisado, distribuido el 27 de abril de 2005, se puede consultar en http://www.globalpolicy.org/security/reform/2005/06methods.pdf) y fue ofrecido como dinamizador del respaldo electoral al proyecto de resolución presentado por la Alianza de los Cuatro (Doc. A/59/PV.111 del 11 de julio de 2005, p. 23). El proyecto de resolución fue distribuido oficiosamente el 3 de noviembre de 2005 (http://www.eda.admin.ch/newyork_miss/e/home/news.ContentPar.0165.UpFile.tmp/xy_y 
mente a la mejora del procedimiento del Consejo de Seguridad, la parquedad en la referencia a estas cuestiones de las demás resoluciones es muy probable que se derive del temor a que la puesta en práctica de estas medidas supongan la superación de la mayoría de las críticas origen y motor de este proceso, convirtiendo en innecesaria o, en poco o nada urgente la incorporación de nuevos miembros al club de los privilegiados, como demostrarían algunas significativas intervenciones ${ }^{25} \mathrm{y}$, en cierta medida, la Declaración Final de la Cumbre Mundial 2005. ${ }^{26}$

Un temor que, sin embargo, no ha jugado en toda su extensión a la hora de que el propio Consejo de Seguridad haya ido mejorando sus métodos de trabajo conforme los avances en el consenso se han ido consolidando alrededor de estos temas en el Grupo de Trabajo de la Asamblea General o a resultas de los desarrollos habidos alrededor del proyecto de resolución del S5. Mejoras que, contando en algunos casos con documentos recopilatorios, ${ }^{27}$ están experimentando un nuevo impulso gracias a la iniciativa de algunas presidencias recientes y al renovado protagonis-

ymmdd_0123456789_1.pdf). De su simple lectura, se aprecia la estrecha relación entre ambos. A su vez, el documento presentado por Suiza, en solitario, encuentra su origen en el estudio solicitado a Luck, Edward, "Reforming the Security Council. Step One: Improving Working Methods", Paper, 25 de abril de 2005, en http://www.sipa.columbia.edu/ cio/cio/projects/Luckworkingmethodsppr.pdf.

25 Véase las intervenciones de Alemania (Doc. A/60/PV.48 del 10 de noviembre de 2005, p. 27) y Francia (Doc. A/60/PV.48, p. 14). Véase, asimismo, Doc. A/60/47, anexo I, p. 6.

26 Si leemos con atención la misma en los parágrafos relativos a la reforma del Consejo de Seguridad, encontramos que las menciones directas son recibidas por los métodos de trabajo, mientras que los temas de composición parecen reducidos a la mención a la representatividad, concepto éste que aparece ligado en la redacción otorgada al de transparencia que formaría parte de los objetivos a obtener con la reforma perseguidos en el grupo de materias II (Doc. A/RES/60/1, parágrafos 153 y 154, p. 35).

27 Véase el Informe de la Secretaría sobre la Evolución de los Procedimientos del Consejo de Seguridad en 2001, Doc. S/2002/603 del 30 de mayo. Posteriormente, el presidente del Consejo de Seguridad, en nombre de todos sus miembros, hacía circular un índice resumido de todas las notas y declaraciones de su presidente relativas a la documentación y al procedimiento del Consejo de Seguridad adoptadas desde 1993 (Doc. A/57/382-S/2002/1000 del 6 de septiembre de 2002). Éste último índice, a petición del Consejo de Seguridad generada por la solicitud de Estados Unidos de América (Doc. S/2005/844 y Doc. S/2005/845, ambos de 29 de diciembre), sería actualizado por la Secretaría y distribuido bajo la Presidencia, precisamente, de Estados Unidos de América (Doc. S/2006/78 del 7 de febrero). 
mo del Grupo de Trabajo oficioso del Consejo de Seguridad sobre Documentación y otras Cuestiones de Procedimiento. ${ }^{28}$

Independientemente de que la razón de tan dispar alcance pueda encontrarse en el deseo de reafirmar que el Consejo de Seguridad es el único dueño de su procedimiento (artículo 30 de la Carta de Naciones Unidas) y de la formalización de las proposiciones de mejora del mismo, ${ }^{29} \mathrm{o}$ en la distinta repercusión mediática de una nota del presidente del Consejo de Seguridad y una resolución de la Asamblea General, lo cierto es que las cuestiones sobre el procedimiento del órgano restringido constituyen la cara más esperanzadora de este proceso en lo que ha propuestas y acuerdo se refiere. $Y$ es que es imposible ignorar que, periodo tras periodo, los documentos de sesión del Grupo de Trabajo de la Asamblea General relativos a las cuestiones conexas se han ido enriqueciendo en alcance y contenido con una variada pléyade de sugerencias sobre las cuales descendía el consenso, convirtiendo a "la cuestión de la moderni-

28 A principios de 2006, a la espera de una decisión definitiva sobre la duración de la Presidencia de este Grupo de Trabajo, se decidía que la presidencia del mismo pasase de un mes a seis (Del 1o. de febrero al 30 de junio de 2006) (Doc. S/2006/66 del 31 de enero, parágrafo 3). Ocupada por Japón, finalmente, hasta el 31 de diciembre, en la actualidad se ha acordado que la misma cuente con una duración de doce meses, siendo la delegación eslovaca la primera en beneficiarse de ello (sobre este acuerdo, véase S/PV.5601 del 20 de diciembre de 2006, pp. 12 y 13, y sobre la elección de la nueva presidencia, Doc. S/2007/20 del 18 de enero). Esto, para revitalizar la acción de este órgano que mantuvo once reuniones entre marzo y julio de 2006, según su presidente y el Informe Anual, Doc. A/61/2, distribuido el 6 de diciembre de 2006, p. 66 (catorce, según los Diarios de Naciones Unidas), y desde entonces, hasta la fecha, siete reuniones de las cuales la última, mantenida el 9 de julio de 2007, cabe suponer tuvo por contenido la preparación del informe de su presidente al Consejo de Seguridad en la consulta de la totalidad mantenida el día siguiente (véase los diarios de Naciones Unidas: Doc. 2006/217 del 10 de noviembre; Doc. 2006/223 del 18 de noviembre; Doc. 2006/232 del 2 de diciembre; Doc. 2007/78 del 24 de abril; Doc. 2007/93 del 15 de mayo; Doc. 2007/107 del 5 de junio; Doc. 2007/130 del 7 de julio; y Doc. 2007/131 del 10 de julio).

29 Uno de los países componentes del S5, Costa Rica, tuvo que dedicar gran parte su intervención en el debate celebrado en el plenario en julio de 2005 para aclarar a los contrarios a una resolución cuyo contenido versase exclusivamente sobre los métodos de trabajo que la adopción por la Asamblea General de la misma no afectaba a la competencia de éste último para modificar sus reglas de procedimiento (Doc. A/60/PV.48 del 10 de noviembre de 2005, pp. 14-17). 
zación y transparencia de los métodos de trabajo del Consejo... en la estrella de las negociaciones". ${ }^{30}$

\section{PROPOSICIONES RECIENTES, PRÁCTICAS Y MANERAS DE ENTENDER EL CONSEJO DE SEGURIDAD}

Por razones obvias, las cuestiones de procedimiento son los indicadores más claros del tipo de órgano ante el que nos hallamos y sus proposiciones de cambio lo son por su parte de la impronta y el carácter que, se pretende, posea. Corresponde, pues, examinar algunos de esos indicadores y de las nuevas características que se desea goce este órgano. ${ }^{31}$

\section{Consejo de Seguridad versus Consejo de Seguridad. Relaciones entre sus miembros}

Desde el final de la Guerra Fría, son múltiples las referencias que podemos encontrar alrededor del ostracismo, tanto informativo como participativo, al que se ha condenado a los miembros no permanentes (a los que se va imponiendo con fuerza denominarlos E-10 o elected 10, en principio, para resaltar su carácter de elegidos y fomentar el descrédito del P-5 o Permanent 5). Ante la extraña situación de que a los miembros no permanentes se les obvie a la hora de elaborar los textos de las resoluciones y declaraciones del presidente del Consejo y éstos siempre concedan su respaldo a los mismos, podríamos buscar explicaciones en el hecho de que estos miembros no permanentes se sientan suficientemente recompensados $^{32}$ con su pertenencia al órgano y con la celebración de

30 Véase Riquelme Cortado, Rosa, La reforma del Consejo de Seguridad de la $O N U$, Madrid, Dykinson, 2000, p. 52. Por su parte, tanto el secretario general (informe: Fortalecimiento de las Naciones Unidas. Un Programa para Profundizar el Cambio, Doc. A/57/387 del 9 de septiembre de 2002, parágrafo 21, p. 9), como los Estados miembros (Doc. A/58/47, anexo IV, parágrafo 53, p. 40) han resaltado este efecto nada colateral de la labor del Grupo de Trabajo.

31 Todas las cuestiones abordadas dentro de este grupo de materias, así como las proposiciones al respecto y los consensos alcanzados sobre ellas, pueden consultarse en el anexo VII del informe contenido en Doc. A/51/47 del 3 de julio de 2003, pp. 52-68.

32 Este discurso se deriva la utilización de la democracia formal (participación del ciudadano limitada a las consultas electorales), completada con el privatismo civil (indiferencia política que promueve las expectativas de recompensas adecuadas), que se produce en el capitalismo tardío a resultas de las crisis de racionalidad, legitimación y moti- 
uno o dos debates temáticos durante su Presidencia, sobre todo, si a los mismos asiste el secretario general. ${ }^{33}$

Sin embargo, en tiempos recientes, parece querer decírsenos que es falaz que los miembros no permanentes estén excluidos, ya que se les consulta sobre los asuntos que afectan a su región, son agentes directos del consenso y, llegado el caso, no les tiembla el pulso a la hora de ejercer el veto de facto, siendo las causas de nuestra "equivocada" impresión la eventual incompatibilidad entre intereses nacionales y regionales, el entendimiento del silencio como excelente maniobra estratégica de negociación o la ausencia de coordinación entre los miembros no permanentes. ${ }^{34}$ Ello significaría, primero, que la argumentación de que el Consejo de Seguridad no es democrático no es tan sólida, desapareciendo gran parte de la justificación de este proceso, ${ }^{35} \mathrm{y}$, segundo, que los posibles déficit de representatividad de este órgano no serán superados cuando aumenten sus miembros, pues el origen de los mismos y la responsabilidad de su superación se encuentran exclusivamente en manos de los miembros no permanentes.

Evidentemente, esta exposición del estado de cosas peca de contradictoria, pues desde la no permanencia se sigue solicitando, por ejemplo, que su consulta se produzca con mayor antelación en aras de disminuir la presentación de las llamadas soluciones "precocinadas", resultado de

vación, y que nos permite traer a colación el razonamiento de la legitimación por dádivas. Sobre ello, se puede consultar Habermas, Jürgen, Problemas de legitimación en el capitalismo tardio, Buenos Aires, Amorrortu Ediciones, 1973, p. 54, y Serrano Gómez, Enrique, Legitimación y racionalización. Weber y Habermas: la dimensión normativa de un orden secularizado, Barcelona-México, Anthropos, 1994, pp. 22-24.

33 La creencia de algunas delegaciones de que estos debates son los que marcan el éxito de su Presidencia del Consejo de Seguridad ha sido puesta de manifiesto en Doc. $\mathrm{S} / 2005 / 228$, p. 4. La confesión de la obsesión de los presidentes por estas reuniones se puede encontrar en el relato que la delegación filipina ha ofrecido de su preparación de la Cumbre del Consejo de Seguridad, celebrada el 14 septiembre de 2005 (disponible en http://www.un.int/philippines/security_council/index_sc.html).

34 Véase Mahbubani, Kishore, "The Permanent and Elected Council Members", en Malone, David M. (ed.), The UN Security Council. From the Cold War to the 21st Century, Boulder, Lynne Rienner Publishers, 2004, pp. 253 y 258, así como Doc. S/2004/135, pp. 3-5.

35 Conferencia de prensa del secretario general, K. Annan, en la presentación de su Informe sobre la Reforma de las Naciones Unidas, extracto reproducido por Túnez en Doc. A/57/PV.30 del 15 de octubre de 2002, p. 5. 
la concertación previa entre los miembros permanentes. ${ }^{36}$ Concertación que, bien es cierto, incluye en ocasiones a algunos Estados privilegiados por aproximación, pero donde esta participación viene a decidirse en función de la condición de potencia o de patrocinador del correspondiente grupo de amigos, lo cual relega a una posición terciaria a los miembros no permanentes. ${ }^{37}$ Por no recordar que el representante de un miembro permanente les calificó como "turistas" 38 y que la censura existe para estos miembros, ${ }^{39}$ aumentando así la desigualdad informativa que sufren.

El hecho de que las verdaderas decisiones se tomen en las consultas oficiosas plenarias o reuniones informales, convertidas las reuniones formales como han sido en meras escenificaciones de votación, más o me-

36 Doc. S/2004/135, p. 5, y Doc. S/2005/228 del 6 de abril, pp. 4 y 5, y 10 . Sobre esta concertación previa de los miembros permanentes, véase Blanc, P. L., "Intervention", en Daudet, Yves (dir.), Aspects du Système des Nations Unies dans le cadre d'un nouvel ordre mondial.Rencontres Internationales de l'Institut d'Études Politiques d'Aix en Provence, 22 y 23 de noviembre de 1991, París, 1992, pp. 79-84, y Delon, Francis, "La concertation entre les membres permanents du Conseil de Sécurité", AFDI, 1993, pp. 53-64. En algunas ocasiones, adquieren un perfil marcadamente institucionalizado, como sucedió con la reunión de sus ministros de Asuntos Exteriores sobre el futuro de Iraq, celebrada el 13 de septiembre de 2003 en Ginebra (véase Press Release SG/SM/8857-IK/ 839 del 9 de septiembre de 2003).

37 Por ejemplo, el 1o. de febrero de 2006, los cinco permanentes y Alemania se reunían en Londres para decidir llevar la cuestión nuclear iraní al Consejo de Seguridad, en lo que no era una práctica novedosa, ya que Alemania y Japón gozan de una participación informal regular en este órgano desde hace tiempo (Hurd, Ian, "Security Council Reform: Informal Membership and Practice", en Russett, Bruce (ed.), The Once and Future Security Council, Harrisonburg, MacMillan, 1997, p. 144). En cuanto al papel y la composición de los grupos de amigos, véase Whitfield, Teresa, "Groups of Friends", en Malone, David M. (ed.), The UN Security Council. From the Cold War to the 21st Century, Boulder, Lynne Rienner Publishers, 2004, pp. 312 y 313. Para ellos se ha solicitado un mayor papel en el Grupo de Trabajo de la Asamblea General (Doc. A/58/47, anexo IV, parágrafo 60 in fine, p. 42).

38 Mahbubani, Kishore, op. cit., nota 34, p. 259.

39 Esta discriminación (calificada de esperpéntica por el profesor A. Remiro Brótons) se produjo cuando, durante la gestación de la agresión a Iraq, los miembros no permanentes tuvieron un solo día para examinar las tres mil quinientas páginas en las que se quedó una declaración iraquí previamente censurada por H. Blix por imposición de los cinco permanentes (véase Remiro Brótons, Antonio, "Carta de las Naciones Unidas-Nuevo Orden: ida y vuelta", en Caflisch, Louis et al. (dirs.), El derecho internacional: normas, hechos y valores. Liber Amicorum José Antonio Pastor Ridruejo, Madrid, Universidad Complutense de Madrid, Facultad de Derecho, Servicio de Publicaciones, 2005, pp. 370 y 371 , nota 43$)$. 
nos perfeccionadas, ${ }^{40} \mathrm{y}$ de que los cambios introducidos en sus métodos de trabajo no sean debidamente institucionalizados, priva a los no permanentes de una memoria institucional necesaria para ejercer su función en toda su extensión.

Para intentar paliarla, a la medida ya adoptada y practicada de incorporar a las consultas oficiosas plenarias uno o dos meses antes del inicio del mandato a los miembros recién elegidos ${ }^{41}$ se añadió, de forma experimental, la celebración regular (incluso diaria) de sesiones informativas oficiosas de la Secretaría de Naciones Unidas sobre las operaciones de paz de Naciones Unidas y otros puntos calientes de la actualidad, ofrecidas a todos los miembros del Consejo de Seguridad, con el propósito de mejorar el sistema de adopción de decisiones y fomentar la disciplina intelectual de sus miembros y de la Secretaría. ${ }^{42}$ Esta medida, fruto de la iniciativa de un miembro permanente, ${ }^{43}$ realmente vino a adicionar perio-

40 De hecho, las reuniones formales en las que se adoptan las resoluciones, se celebran exclusivamente con ese objetivo, permitiéndose por regla general la intervención exclusiva de los miembros del Consejo para explicar su voto, aunque en ocasiones ha habido excepciones. Circunstancia ésta que llevó a la delegación sudanesa a plantear sus quejas al presidente de turno, la delegación de Filipinas, por no haber sido invitada a la reunión en la que se adoptó la Resolución 1547 (2004) del 11 de junio. Ante las quejas recibidas alrededor de su diligencia, en el tratamiento de la cuestión, el presidente le hizo saber que, a su pesar, los miembros del Consejo no habían alcanzado el consenso en ese sentido, y le recordó que fue él mismo quien recomendó que presentara su intervención para que fuera distribuida oficialmente, como así fue (véase Doc. S/2004/490 del 16 de junio, y Doc. S/2004/498 del 17 de junio).

41 Véase Notas del presidente del Consejo de Seguridad, Doc. S/2000/155 del 28 de febrero; Doc. S/2002/1276 del 22 de noviembre; y Doc. S/2004/939 del 2 de diciembre.

42 Éstas comenzaban a las diez de la mañana. Tras una exposición de cinco a quince minutos, el debate entre miembros y Secretaría podía abarcar entre treinta y cuarenta y cinco minutos de debate. Véase la trascripción de la rueda de prensa ofrecida por J. R. Bolton, con motivo de la presentación del Programa de Trabajo del Consejo de Seguridad para febrero, celebrada el 2 de febrero de 2006, disponible en http://www.un.int/usa/ 06print_014.htm, y Lederer, E. M., "UN Council to give Bolton Daily Updates", Houston Chronicle del 4 de febrero de 2006, disponible en la siguiente página http://www. chron.com/disp/story.mpl/ap/nation/3635992.html.

43 En su primer y último término como presidente del Consejo, tras su polémica designación como representante permanente de Estados Unidos de América, J. R. Bolton se mostró especialmente activo en las cuestiones de procedimiento del órgano restringido, en lo que pudo ser el deseo de imprimir al Consejo de Seguridad del espíritu eficiente y eficaz que se cree propio y exclusivo, el intento de equilibrar los vaivenes que los temas elegidos para los debates temáticos para su mes de presidencia generaron (véase infra) o 
dicidad y puntualidad a unas sesiones que ya existían y a enriquecerlas con la intención de su promotor de contribuir, informativamente hablando, a las mismas. Características que, sin embargo, no se consideraron suficientes para garantizar su continuidad. ${ }^{44}$

Otras posibles soluciones permanecen, desgraciadamente, inexploradas como son las consultas periódicas o más frecuentes entre los miembros no permanentes, que servirían para que los recién incorporados fuesen informados por los que se hallan a mitad de mandato, ${ }^{45}$ el acceso de los miembros del Consejo a las notas que se prepara al secretario general sobre las consultas oficiosas plenarias a las que éste no puede asistir o el suministro de información sobre consultas oficiosas anteriores a su entrada en el Consejo. ${ }^{46}$

Desde el plano funcional, esta desorientación ha fortalecido la reclamación de la institucionalización de los métodos de trabajo actuales $\mathrm{y}$, por tanto, de todos los cambios habidos desde la última modificación de sus Reglas Provisionales de Procedimiento. ${ }^{47}$ A pesar de los intentos de incrementar la transparencia sobre estas mejoras, practicadas la mayoría de ellas a través de notas y declaraciones presidenciales, ${ }^{48}$ la actualización del reglamento del Consejo de Seguridad y la eliminación del ad-

el de recuperar el extenso terreno perdido como líder mundial a consecuencia de las decisiones adoptadas, dentro y fuera de los muros de Naciones Unidas, en los últimos años (véase Remiro Brótons, Antonio, op. cit., nota 39, pp. 359-382, y Sánchez Rodríguez, Luis Ignacio, Derecho internacional y crisis internacionales, Madrid, Iustel, 2005).

44 Las mismas dejaron de celebrarse el mes siguiente, bajo la Presidencia de Argentina, ante el volumen de trabajo que presentaba el órgano restringido (Press Conference by the Security Council President del 2 de marzo de 2006).

45 Doc. $\mathrm{S} / 2005 / 228$, p. 3.

46 Tanto en 2001, como en 2004, la Secretaría mantiene que éstas son de uso exclusivo de la Secretaría y no hacen fe (Nota de la Secretaría de 12 de julio de 2001 referente a las Prácticas de Levantamiento de Actas en la Secretaría del Consejo de Seguridad (Doc. A/AC.247/2001/CRP.8 del 20 de julio de 2001, en Doc. A/55/47 del 9 de septiembre de 2001, parágrafo 5, p. 183, y Doc. S/2005/228, p. 9). En su momento, ya le fue solicitado a la Secretaría un informe sobre su régimen de acceso, presente y futuro, para miembros del Consejo y de Naciones Unidas y para investigadores externos, al igual que sobre su política de almacenamiento, gestión y conservación, ya que las mismas han sido en ocasiones destruidas para ganar espacio (véase la propuesta de Granada en Doc. A/AC.247/2001/CRP. 9 del 20 de julio de 2001, en Doc. A/55/47 del 9 de septiembre de 2001, pp. 184 y 185$)$.

47 Doc. S/96/Rev.7, última revisión formal resultante de la Resolución 528 (1982) del 21 de diciembre.

48 Véase supra nota 27. 
jetivo "provisional" de su denominación siguen resultando imperantes y su falta de realización, aparentemente debida a la preferencia por la tradición jurídica anglosajona ${ }^{49}$ reprochable. La elaboración por la Secretaría de Naciones Unidas de un detallado paquete informativo sobre los procedimientos, prácticas y trabajo del Consejo de Seguridad para los miembros recién elegidos ${ }^{50} \mathrm{o}$ el fortalecimiento de la División de Asuntos del Consejo de Seguridad del Departamento de Asuntos Políticos, ${ }^{51}$ podrían ser formas de evitar que éstos se "arrastrasen", al menos, en los primeros meses de su mandato, ${ }^{52}$ pero resultan insuficientes y poco adecuadas a una buena técnica jurídica. Se ha de insistir, pues, en la oportunidad y conveniencia de la sistematización de sus métodos de trabajo en un único documento, sus Reglas de Procedimiento, sean cuales fueren las vías formales que el órgano restringido decida utilizar para su reforma (resoluciones, declaraciones o notas presidenciales),$^{53}$ pues será en dichas Reglas y en su sistema de adopción, en el que no juega el derecho de veto al

49 Véase la intervención de Costa Rica en que muestra su desacuerdo con dicha argumentación (Doc. A/60/PV.48, p. 15).

50 Borrador de resolución del S5, anexo, parágrafo 18.

51 Si hay una función valorada, sobre todo por los miembros no permanentes, que goce de amplio consenso entre todos los miembros que se han pronunciado sobre ella, esa es la labor de memoria institucional que respecto de las prácticas pasadas y protocolos existentes desarrolla esta división (véase Report of the Office of Internal Oversight Services on the in-Depth Evaluation of Political Affairs: Security Council Affairs, Doc. E/AC.51/2007/2/Add.2 del 29 de marzo, pp. 7 y 8).

52 Doc. S/2004/135, pp. 5 y 6.

53 La institucionalización a través de la reforma de sus Reglas de Procedimiento ha sido reclamada por el Grupo de Alto Nivel (Doc. A/59/565, parágrafo 258 in fine, p. 77), el Grupo Unidos para el Consenso (Doc. A/59/L.68, parágrafo 7 e)), el S5 (al menos, en lo que respecta a las mejores prácticas del Consejo a la hora de consultar a los no miembros. Véase su borrador de resolución, anexo, parágrafo 17), y algunas delegaciones gubernamentales (Doc. A/59/47, anexo II, parágrafo 9, p. 8). En su momento, Chile, Costa Rica, Egipto, Guinea-Bissau, Japón, Kenia, Polonia, Portugal, República de Corea y Suecia, por aquel entonces miembros no permanentes, reclamaron la revisión de estas reglas (Doc. A/AC.247/1999/CRP.8 del 29 de julio de 1999, apéndice I y apéndice II, parágrafo 1, en Doc. A/53/47 del 5 de agosto de 1999, pp. 59 y 61), aunque no acompañaron sus palabras con hechos. Por su parte, en el Grupo de Trabajo de la Asamblea General, el consenso sobre la institucionalización existe, si bien no se predica respecto de una única vía (el acuerdo parece dividido entre las reglas de procedimiento y las declaraciones de su presidente, aunque en ningún caso alrededor de las notas de éste último). Véase también Doc. A/57/47 del 3 de julio de 2003, último informe en el que se transcribieron todas las propuestas vigentes de reforma. 
ser una cuestión pura de procedimiento, ${ }^{54}$ donde esté garantizado el dinamismo en el actuar de este órgano, y no en la inseguridad y la opacidad predicadas de sus métodos de trabajo, como voces anónimas parecen defender. ${ }^{55}$

\section{La búsqueda de la comunicación y coordinación entre los órganos principales.}

Dada la generalidad, envergadura y complejidad de realización de las funciones de Naciones Unidas en la actualidad, el establecimiento entre sus órganos principales de un diálogo fluido, cooperativo y constructivo resulta fundamental para el desarrollo eficiente y eficaz de aquéllas. De todas las realizadas, la mayoría de sugerencias han ido dirigidas al diálogo mantenido con la Asamblea General, seguidas por el sostenido con el Consejo Económico y Social y, por último, a una considerable y criticable distancia con la Corte Internacional de Justicia, lo que resulta altamente llamativo si tenemos presente que las reclamaciones vigentes sobre la relación entre órgano restringido y órgano plenario se han centrado principalmente en la rendición de cuentas, y que, dentro de las críticas a superar con esta reforma, se encuentran las referidas a la actuación parcial y ultra vires del Consejo de Seguridad y el posible control de su acción. ${ }^{56}$

En cuanto a la relación entre Asamblea General y Consejo de Seguridad, las propuestas de perfeccionamiento de la rendición de cuentas han girado alrededor de la mejora de las vías de suministro de información al órgano plenario y, más exactamente, sobre la potenciación del carácter analítico y sustantivo del informe anual del Consejo de Seguridad y la efectiva presentación de los informes especiales. Así, aunque el informe anual ha experimentado ciertas mejoras, como la conversión de su intro-

54 El recordatorio no es ocioso, máxime si tenemos presente que, en tiempos recientes, se permite y acata la interposición del veto amagado para cuestiones de procedimiento, como fue el caso de la negativa estadounidense a que el Consejo de Seguridad estableciese un diálogo institucional constante y fluido con la Corte Internacional de Justicia. Véase Mahbubani, Kishore, op. cit., nota 34, p. 259.

55 Doc. S/2005/228, p. 15.

56 Véase López-Jacoiste Díaz, María Eugenia, Actualidad del Consejo de Seguridad de las Naciones Unidas. La legalidad de sus decisiones y el problema de su control, Madrid, Civitas, 2003. 
ducción en lo que podemos considerar la única parte analítica que aporta información novedosa en el momento de presentación del informe anual, ${ }^{57}$ la opinión mayoritaria es que éste no permite entender el origen y motivo de la acción asumida por el Consejo de Seguridad. Elemento esencial si se quiere fomentar el cumplimiento de la misma y la consideración del órgano como legítimo. ${ }^{58}$ La posibilidad de subsanar este déficit mediante el desarrollo de esa parte introductiva hasta convertirla en la única que sería distribuida con carácter general, manteniendo el resto como archivo disponible en la página Web del Consejo de Seguridad, aun cuando supondría una reducción en sus costes de elaboración, ${ }^{59}$ está ausente de estos trabajos, quizá debido al aviso de que una profundización en el contenido sustantivo de este informe plantearía problemas en su adopción. ${ }^{60}$ Inconveniente que, por lo demás, podría superarse si se permitiese que esos contenidos fuesen elaborados por los coordinadores políticos, responsables casi exclusivos de la ejecución diaria del programa de trabajo del Consejo de Seguridad, y se acogiesen las propuestas de presentación más frecuente de informes de esta naturaleza. ${ }^{61}$ Por el mo-

57 Esta transformación se produjo a partir del Informe Anual, Doc. A/57/2 del 27 de septiembre de 2002. La primera fue elaborada por el Reino Unido, que compartió esa función en el periodo siguiente con España. Elaboración por determinados miembros del Consejo que tuvo el respaldo del Grupo de Trabajo Oficioso del Consejo sobre Documentación y Cuestiones de Procedimiento (información extraída de la Evaluación Mensual de la Labor del Consejo de Seguridad durante la Presidencia Mexicana, ejercida en abril de 2003, Doc. S/2003/763 del 28 de julio, pp. 14 y 15). La parte introductoria del último informe del órgano restringido fue preparada por Francia (Doc. S/PV.5578 del 6 de diciembre de 2006, p. 2). En general, la mayoría de contenidos del informe anual ya han estado a disposición de los Estados miembros antes de la elaboración del mismo, siendo por tanto su principal función la de sistematizar y compilar la misma. La preparación del resto del informe es gestionado por un funcionario superior del cuadro orgánico, apoyado por un equipo compuesto por un funcionario del cuadro orgánico y dos del cuadro de servicios generales de la División de Asuntos del Consejo de Seguridad del Departamento de Asuntos Políticos (véase Doc. E/AC.51/2007/2/Add.2, p. 12).

58 Peticiones, en este sentido, pueden ser encontradas en Doc. A/60/L.46, parágrafo 8 h).

59 En 2001, Singapur nos informaba que cada página del informe costaba seiscientos dólares (Doc. S/PV.4375 del 18 de septiembre de 2001, p. 3). En 2002, afirmaba que cada página suprimida del informe suponía un ahorro de mil dólares (Doc. S/PV.4616 del 26 de septiembre de 2002, p. 3).

60 Doc. A/59/47, anexo II, parágrafo 5, p. 7.

61 Véase Doc. S/2004/135, p. 16, Documento de sesión preparado por la Mesa del Grupo de Trabajo (Doc. A/AC.247/1996/CRP.4 de 16 de abril de 1996, epígrafe III.1, 
mento y en lo que podría suponer una rémora para las mejoras al respecto, se ha lanzado una iniciativa fuera de los muros de Naciones Unidas, denominada Security Council Report, con la finalidad de suministrar una información completa, sustantiva y actualizada de la acción del órgano restringido. ${ }^{62}$

Otra sugerencia para superar esta insuficiencia informativa es que los miembros del Consejo de Seguridad se impliquen en un debate informal e interactivo de este informe anual en el órgano plenario. ${ }^{63}$ Medida que tendría mayor razón de ser si en el órgano plenario se hubiese instaurado este tipo de debate sobre el informe anual e interpelado al presidente del Consejo de Seguridad, que desde mediados de la década de los noventa del siglo XX presenta el informe ante la Asamblea, o a algunos de sus miembros a suministrar mayor información y éstos se hubiesen negado. Ninguna de estas dos situaciones se ha producido y, de hecho, cabe plantearse si ocurrirá en breve ya que la elaboración de una evaluación del debate del informe anual que, en su caso, pudiese dar entrada a la celebración de consultas informales entre los miembros de la Asamblea para formular recomendaciones al respecto al Consejo o a la formulación de las mismas directamente por su presidente, ${ }^{64}$ tardó alrededor de cinco años en ser puesta en práctica, sin que exista certeza sobre su plena instauración. ${ }^{65}$

parágrafo 1 (c), en Doc. A/50/47/Rev.1 del 31 de enero de 1997, p. 24), y la intervención de la Antigua República Yugoslava de Macedonia (Doc. A/54/PV.35 del 20 de octubre de 1999 , pp. 16 y 17).

62 Esta iniciativa surgida de Canadá, Noruega, el otrora representante permanente de Nueva Zelanda, Colin Keating, y diversas fundaciones, ha tenido como resultado una organización no lucrativa asociada con la Universidad de Columbia, cuya página es http://www.securitycouncilreport.org/.

63 Borrador de resolución del S5, anexo, parágrafo 1.

64 Doc. A/RES/51/241 del 31 de julio de 1997, parágrafo 12, y Doc. A/RES/58/126 del 19 de diciembre de 2003, parágrafo 4.

65 Véase Doc. A/58/PV.36 del 17 de octubre de 2003, pp. 15 y 16. En el sexagésimo periodo de sesiones, esta evaluación no ha sido efectuada, salvo que se considere como tal, a nuestro juicio equivocadamente, el resumen de los debates sobre la reforma del Consejo con el que el presidente de la Asamblea General consideraba cumplido el mandato de examinar la evaluación de esta cuestión a finales de 2005, contenido en el parágrafo 153 in fine de la Declaración Final de la Cumbre Mundial 2005 (Doc. A/RES/60/1). Dicha recapitulación se encuentra en la Carta sobre la Aplicación de la Declaración Final de la Cumbre Mundial 2005. Evaluación de los Progresos en la Reforma 
Por ende, podrían explorarse en mayor medida dos vías ya conocidas. Una de ellas es el debate de adopción del informe anual en el propio Consejo de Seguridad. Una reunión formal pública donde los miembros del Consejo de Seguridad pueden completar o dar un revestimiento más sustantivo a los datos sistematizados en el texto del informe que fue celebrada por primera y única vez en $2002 .{ }^{66}$ La segunda, los debates de recapitulación. Reuniones formales públicas o privadas, abiertas, celebradas con irregular periodicidad, destinadas a la reflexión y obtención de conclusiones sobre la acción del órgano restringido desarrollada bien durante el mes de la Presidencia organizadora (como ocurría en un principio), bien durante el año (hasta el momento, sólo se ha celebrado uno con este alcance), bien sobre un tema concreto (los más frecuentes en los últimos tiempos y que presentan evidentes similitudes con los debates temáticos), ${ }^{67}$ que mejoran la comprensión de la acción del Consejo de Seguridad y permitirían la formulación de sugerencias de perfeccionamiento. Un recurso que, en aras de una buena utilización de los medios y el tiempo del órgano restringido, debería perfeccionarse a través de la generalización de la práctica de invitar a los presidentes de la Asamblea General y del Consejo Económico y Social (lo que favorecería el intercambio de opiniones entre estos tres órganos principales con carácter periódico y con un procedimiento tipo, tal y como ha sido solicitado con carácter autónomo dentro de este proceso de reforma $)^{68}$ y de la discusión sobre el contenido de las evaluaciones mensuales de su presidente (que

del Consejo de Seguridad del 19 de diciembre de 2005 (http://www.globalpolicy.org/se curity/reform/cluster1/2005/1219progress.pdf).

66 Véase Doc. S/PV.4616 y Corr.1 del 26 de septiembre de 2002. Las delegaciones de Singapur y Colombia fueron en gran parte las responsables de esta conveniente medida. El último informe fue aprobado por el Consejo de Seguridad, el 6 de diciembre de 2006 (Doc. S/2006/942 del 7 de diciembre).

67 Véase, dentro de la página de la Presidencia del Consejo de Seguridad, el enlace relativo a estos debates (http://www.un.org/spanish/docs/presidency/). Página de la Presidencia que fue habilitada gracias a la petición de Jamaica, poco antes de su ocupación en dicho cargo en noviembre de 2001. Véase "Objetivos de Jamaica durante el periodo que ocupe la Presidencia del Consejo de Seguridad, noviembre 2001”, Doc. S/2001/1055 del 8 de noviembre, p. 4).

68 Esta invitación se produjo en el debate de recapitulación celebrado por México sobre el tema "Naciones Unidas después de los conflictos" (Doc. S/PV.4748 del 30 de abril de 2003). La petición de ese intercambio de puntos de vista entre los tres órganos se encuentra en las últimas evoluciones, en el borrador de resolución del S5, anexo, parágrafo 3 . 
podrían ser presentadas también a la Asamblea General, materializando así la propuesta de presentación más frecuente y sustantiva de los contenidos del informe anual) o, si así lo deciden, de temas concretos que sirvan para la preparación de los informes especiales previstos en el artículo 24.3 de la Carta, acogiendo de esta manera otra de las sugerencias más reiteradas en este proceso, ${ }^{69}$ que está intentando ser fomentada desde la propia Asamblea General. ${ }^{70}$

Por lo que respecta a esa práctica de invitar a los presidentes de los otros dos órganos, ha de apreciarse que ello también incidiría positivamente en la correcta delimitación del ejercicio de las correspondientes competencias. Así, en el plano gubernamental, existía cierta resistencia a la ampliación/usurpación de funciones del Consejo de Seguridad que, conforme nos hemos distanciado de los atentados terroristas del 11 de septiembre de 2001, ha ido aumentando y volviéndose más explícita. Sin embargo, la valoración del alcance y significación de dichas alocuciones se veía enormemente dificultada porque esa oposición se veía en la mayor parte de las ocasiones matizada (cuándo no, casi anulada) cuando sus protagonistas intervenían en el órgano restringido. ${ }^{71}$ Fue, a principios de 2006, cuando la situación se empezó a clarificar.

El Movimiento de los No Alineados, el Grupo de los 77 (más China) y el Grupo Africano, mostraron expresamente su preocupación por la intrusión continua del Consejo de Seguridad en las funciones de la Asamblea General y del Consejo Económico y Social, especialmente respecto a la primera y, más concretamente, de sus competencias relativas al establecimiento de normas y formulación de definiciones y los procedimien-

69 La presentación de estos informes especiales se ha reclamado, tanto en términos generales, como al indicar sus posibles temáticas. Así, el S5 ha solicitado que los mismos versen sobre asuntos que actualmente preocupen a la comunidad internacional, como la terminación de las operaciones de mantenimiento de la paz, la imposición de medidas de coerción o cualquier otra de relevancia para la generalidad de los miembros de Naciones Unidas (Borrador de resolución, anexo, parágrafo 2).

70 Así, en la Resolución 59/313 del 12 de septiembre de 2005, el órgano plenario decidía invitar al Consejo de Seguridad a que se presentase informes especiales de carácter temático sobre las cuestiones de interés internacional del momento, así como informes sobre las medidas adoptadas o en vías de adopción sobre la mejora de elaboración de estos textos, y celebrar debates interactivos, cuando todos éstos fueran presentados (parágrafo 2 c)-f))

71 Véase mi trabajo "Sombras y luces en las dos dimensiones de la reforma del Consejo de Seguridad", op. cit., nota 1. 
tos financieros y presupuestarios de las operaciones de mantenimiento de la paz. Su desasosiego, además, se acompañó de la solicitud de pleno respeto de la Carta de Naciones Unidas, de la asimilación por los miembros del Consejo de Seguridad del mandato de representación que se establece en su artículo $24 \mathrm{y}$, consiguientemente, de su necesaria rendición de cuentas a la Asamblea General. ${ }^{72}$ En el origen de todo ello se encuentra la celebración de dos debates temáticos sobre la gestión y adquisición de las operaciones de mantenimiento de la paz y la explotación y abusos sexuales en dichas operaciones, a propuesta de la Presidencia estadounidense.

Empero, el enfrentamiento, para esta última delegación, fue sólo aparente porque el Consejo tiene competencias sobre las operaciones de mantenimiento de la paz y todos los aspectos que puedan afectar a la autorización de éstas caen dentro del marco legal fijado para su actuación, ${ }^{73}$ habiendo sido la intención última de estos debates tomar la iniciativa en la discusión y comprobar cómo sería la mantenida en su caso en la Asamblea General. De hecho, así se lo comunicó al presidente de la Asamblea General y al entonces todavía secretario general, Kofi Annan, que no se presentó excesivamente conforme con la decisión estadouniden-

72 Malasia, en nombre del Movimiento de los No Alineados, presentaba la Carta del 3 de febrero de 2006 (Doc. S/2006/85 del 10 de febrero), en la cual se contiene la posición de principio sobre esta relación entre los órganos principales y la usurpación de funciones por el Consejo de seguridad, y la Carta del 14 de febrero de 2006 (Doc. A/60/679 del 15 de febrero de 2006), en la que la posición se concretaba respecto de estos asuntos, y se solicitaba al presidente de la Asamblea General el mantenimiento de consultas conforme a la Resolución 58/126, con su homónimo del Consejo. El Grupo de los 77 y China plantearon su oposición sólo respecto de las adquisiciones de las operaciones de mantenimiento de la paz, y a raíz de solicitar la participación del delegado de Sudáfrica como representante en el debate relativo a esta cuestión (Carta del 17 de febrero, Doc. S/2006/113 del 21 de febrero). El Grupo de Estados Africanos manifestaba que ambos debates eran "una intromisión" en las funciones del órgano plenario e incompatibles con los debates sobre la revitalización de ésta (reclamada también en el Grupo de Trabajo de la Asamblea General, Doc. A/58/47, anexo II, parágrafos 45, 50 y 53, pp. 39 y 40), e hizo un llamamiento a J. Eliasson en el mismo espíritu que el efectuado por los No Alineados (Carta del 20 de febrero, Doc. A/60/688 del 22 de febrero de 2006).

73 En lo que fue una argumentación también esgrimida en la última edición celebrada del curso práctico anual "Eficacia inmediata" (Doc. S/2007/137 del 12 de marzo, pp. 4 y 14). 
se ${ }^{74}$ consciente de que las modificaciones presupuestarias podían no encontrarse muy lejos. ${ }^{75}$

Independientemente de que estos debates supusieran o no un ejemplo más de esa usurpación, del fuego cruzado que se produjo alrededor de ellos ${ }^{76}$ y de que los debates alrededor de la usurpación de funciones se hayan reproducido con posterioridad, ${ }^{77}$ ha de tenerse presente que los programas mensuales de trabajo suelen ser negociados entre todos los miem-

74 Véase la rueda de prensa que, como presidente del Consejo, otorgó J. R. Bolton, el 17 de febrero de 2006, disponible en http://www.un.int/usa/06_029.htm), así como la Daily Press Briefing by the Offices of the Spokesman for the Secretary-General and the Spokesperson for the General Assembly President, de igual fecha, en http://www.un.org/ News/briefings/docs/2006/db060217.doc.htm.

75 Estados Unidos de América contribuye con un 27\% al presupuesto de estas operaciones y, a nivel interno, ha comenzado la preparación de la ofensiva para el recorte de esta cuota (véase Allen, V., "Senate votes to cut U.S. Share of U.N. Peacekeeping", Reuters, 6 de abril de 2005, consultado en http://www.reuters.com).

76 El Grupo de los 77 había enviado una misiva al secretario general, en donde se recriminaba por segunda vez en el periodo de sesiones, que los informes sobre cuestiones presupuestarias fuesen comentados a la prensa por miembros de la Secretaría, antes de su distribución a los Estados miembros, y recordaba que los despidos generados por los mismos debían cumplir los debidos parámetros legales (véase las cartas dirigidas por Jamaica y Sudáfrica, y distribuidas como Doc. A/60/548 del 9 de noviembre de 2005, y Doc. A/60/675 del 9 de febrero de 2006). Esta segunda intervención generó las acusaciones de obstruccionismo, en la acción contra la corrupción lanzadas por los congresistas H. J. Hyde y T. Lantos (Carta del 16 de febrero de 2006, disponible en http://www.eyeontheun. org/assets/attachements/documents/Letter_from_Rep_Hyde_and_Rep_Lantos_to_the_G77 and_China.pdf), contestadas en la carta en la que se expresó la posición de- Grupo (nota 71).

77 Otros dos ejemplos al respecto han venido constituidos por los casos de Myanmar y el debate temático sobre cambio climático. En el caso de Myanmar, la cuestión de la usurpación de competencias ya se planteó a raíz de su inclusión en el programa de trabajo de la Asamblea General (Doc. S/PV.5526 del 15 de septiembre de 2006), a la cual se opusieron, entre otros, China y la Federación de Rusia, y se recrudeció cuando las delegaciones estadounidense y británica plantearon un proyecto de resolución (S/2007/14 del 12 de enero) que recibió dos vetos de esos dos mismos países, justificados en la usurpación y solapamiento con el mandato de otros órganos y organismos de la familia de Naciones Unidas (Doc. S/PV.5619 del 12 de enero de 2007, pp. 2 y 3, y 6). En el supuesto del cambio climático, la proposición del Reino Unido de celebrar este debate temático generó tal oposición dentro y fuera del Consejo de Seguridad que esta delegación tuvo que garantizar que ninguna acción sería adoptada como conclusión de mismo, en lo que supuso una clara diferencia con el resto de debates temáticos que suelen recibir como broche final la adopción de una declaración presidencial (véase Doc. S/PV.5663 y 5663 (Reanudación 1) del 17 de abril de 2007). 
bros del Consejo y que algunos de los miembros permanentes que han decidido alzar la voz sobre este extremo no han sido de los miembros más comprometidos con el levantamiento de vallas a la acción desbocada de este órgano, lo cual matiza enormemente su grado de preocupación, circunscrita, por lo demás, a la alteración del principio de división del trabajo entre los órganos principales. ${ }^{78}$ Sin embargo, estos ejemplos muestran una mayor disposición a hacer valer la protesta en este sentido, quizá ante la sospecha de que el mantenimiento en la ambigua oposición podría fortalecer la reclamación de nuevos asientos permanentes como forma de de hacer más legítima y representativa la acción extracompetencial del Consejo de Seguridad

Por otra parte, si bien en estas reclamaciones de contención la referencia al debido respeto a las competencias del Consejo Económico y Social ha sido concisa, no se puede mantener que haya sido ocasional. Las relaciones entre ambos órganos restringidos han sido objeto y ejemplo de mejoras en su desarrollo principalmente a través de la interacción entre el Grupo de Trabajo ad hoc sobre la prevención y la solución de conflictos en África ${ }^{79}$ y los Grupos Consultivos Especiales del Consejo Económico y Social sobre Guinea Bissau y Burundi, ${ }^{80}$ asentada sobre la participación mutua en los respectivos trabajos (institucionalizada en el caso la intervención del presidente del Grupo de Trabajo en la labor de los Grupos Consultivos Especiales), las continuas referencias a la acción de los segundos en las resoluciones y declaraciones del presidente del Consejo de Seguridad, la invitación al presidente del Consejo Económico y Social para intervenir en algunas reuniones del Consejo de Seguridad (por otra parte, no sólo relacionadas con África) y el establecimiento de misiones conjuntas a este continente. ${ }^{81}$ Cooperación y coordinación que,

78 Véase la tercera observación de la intervención de China en Doc. S/PV.5376 del 22 de febrero de 2006, p. 8.

79 Establecido por la Nota del presidente del Consejo de Seguridad, Doc. $\mathrm{S} / 2002 / 207$ del 1o. de marzo. Su mandato se ha visto renovado hasta el 31 de diciembre de 2007 (Doc. S/2007/6 del 8 de enero).

80 Dentro del marco señalado por la Resolución 2002/1 del 15 de julio, del Consejo Económico y Social, la decisión 2002/304 del 25 de octubre, estableció el Grupo Consultivo Especial sobre Guinea Bissau, y la decisión 2003/16 del 21 de julio, hizo lo propio con el relativo a Burundi, fijándose en ellas su composición.

81 Véase una exposición resumida de esta relación en el Informe del Secretario General sobre la Evaluación de los Grupos Consultivos Especiales del Consejo Económico y Social sobre Países de África que salen de Situaciones de Conflicto, Doc. E/2004/86 
considerada respetuosa con las competencias individuales por parte del propio Consejo Económico y Social, se espera que salga fortalecida y ampliada, por lo que a la plena aplicación del artículo 65 de la Carta se refiere, de la que se establezca en el marco de la Comisión de Consolidación de la Paz. ${ }^{82}$

En cuanto a la comunicación con la Corte Internacional de Justicia, como apuntábamos, este proceso en poco o nada va a variar el estado de cosas actual. La propuesta formulada en el Grupo de Trabajo de la Asamblea General alrededor de la posibilidad de establecer una revisión judicial en los supuestos en que pudiese existir una controversia entre los miembros del Consejo de Seguridad y el resto de miembros acerca de una actuación ultra vires del Consejo fue, desgraciadamente, flor de un periodo de sesiones. ${ }^{83}$ La que abogaba genéricamente por un mayor recurso del órgano político a la competencia consultiva del órgano judicial respecto de cuestiones jurídicas, aun poseedora del consenso, no ha sido recordada en los últimos periodos de sesiones. ${ }^{84}$ Es más, la práctica de las exposiciones informativas por parte del presidente de la Corte Internacional de Justicia a los miembros del Consejo de Seguridad en reunión formal privada, después de tres años consecutivos de experimentación, fue abandonada. ${ }^{85}$

del 25 de junio, así como una muestra de la misma en la Carta del 2 de Noviembre de 2004 dirigida al Presidente del Consejo de Seguridad por el Presidente del Consejo Económico y Social (Doc. S/2004/898 del 15 de noviembre).

82 Tal y como lo apuntaron el presidente del Consejo Económico y Social, Working Paper on Implementation of 2005 World Summit Decisions Regarding Economic and Social Council, octubre 2005, parágrafo 26, p. 7 (en http://www.un.org/docs/ecosoc/documents/2005/ECOSOCSummitfollow_up.pdf), y el presidente del Grupo de Trabajo Ad Hoc sobre la Prevención y la Solución de Conflictos en África, en su Informe Anual de 2005 (Doc. S/2005/833 del 30 de diciembre, parágrafos 8 y 17, pp. 5 y 7).

83 Doc. A/58/47, anexo IV, parágrafo 63, p. 42.

84 La última referencia se encuentra en Doc. A/AC.247/2003/CRP.3 (revisado) del 24 de abril de 2003, parágrafo 33, en Doc. A/57/47 del 3 de julio de 2003, p. 66, y Doc. A/59/47, anexo II, parágrafo 11, p. 9.

85 El periodo de su práctica fue de 2000-2002. Sobre el origen de este abandono, véase nota 54 . 


\section{El perfeccionamiento de sus órganos subsidiarios}

La ampliación y sobrecarga de la agenda del Consejo de Seguridad es, a su vez, el origen y la consecuencia de "la explosión" 86 en el establecimiento de órganos subsidiarios del mismo y de su gran variedad. El Comité de Estado Mayor, operaciones de mantenimiento de la paz, tribunales internacionales, comisiones varias, comités de sanciones, grupos de expertos o grupos de trabajo asumen gran parte de la acción acordada por los miembros del órgano principal haciendo de su necesidad de transparencia, apertura o toma en consideración de las posiciones del resto de Estados miembros, un aspecto tan trascendental como la del órgano que los establece. ${ }^{87}$ Una valoración que, autónoma o inducidamente, también ha compartido el propio Consejo de Seguridad, como se ha puesto de relieve en las sucesivas medidas que con el objeto de mejorar los procedimientos de estos órganos ha ido adoptando, no siempre, ni en todo caso en consonancia con las peticiones que desde diversos frentes se le requerían.

Esta proliferación no sólo repercute en unas necesidades financieras cada vez mayores (por número y complejidad de mandatos), sino también en la insatisfacción de algunas de ellas, lo cual lleva a que estos órganos no siempre cuenten con los medios necesarios para poder actuar eficazmente. Ello, en algunos supuestos, deriva en la imposibilidad de satisfacer dudas o interrogantes planteados por el resto de Estados miembros de la Organización, generando consternación, hastío y, a la larga, incrementando el riesgo de incumplimiento de las obligaciones que pesan sobre ellos. ${ }^{88}$ Situación que se agrava, primero, por la falta de coordinación y duplicaciones en los esfuerzos que, en ocasiones, se derivan de sus cada vez más amplios mandatos y, segundo, porque el Consejo de Seguridad no suele seguir con la debida atención la labor que desempeñan, ahondando así en la sensación de orfandad que, en ocasiones, embarga a sus miembros. ${ }^{89}$ De ahí la solicitud de racionalización en el

86 Véase Bailey, Sydney D. y Daws, Sam, The Procedure of the Security Council, 3a. ed., Oxford, Clarendon Press, 1998, p. 334.

87 Doc. S/2007/137, pp. 9, y 11 y 12.

88 Doc. S/2005/228, p. 8, así como el Informe del Grupo de Trabajo Oficioso del Consejo de Seguridad sobre Cuestiones Generales relativas a las Sanciones, Doc. S/2005/842 del 29 de diciembre, parágrafo 18, p. 7.

89 Doc. $\mathrm{S} / 2005 / 228$, p. 7. 
establecimiento y uso de órganos subsidiarios y correspondientes mecanismos de apoyo. ${ }^{90}$ Una solicitud que, por lo demás, ha encontrado una vía parcial de realización en el requerimiento de los jefes de Estado y de Gobierno en el Documento Final de la Cumbre Mundial 2005 al órgano plenario y otros órganos relevantes de Naciones Unidas de revisar todos los mandatos con una duración mayor a cinco años en aras de fortalecer, actualizar y ajustarse mejor a las necesidades y solicitudes de los Estados miembros, ${ }^{91} \mathrm{y}$ en el correspondiente informe del secretario general, titulado Los Mandatos y su Ejecución. Análisis y Recomendaciones para facilitar el Examen de los Mandatos. ${ }^{92}$ Tarea de revisión que, en el órgano restringido, le ha sido otorgada al Comité ad hoc sobre revisión de mandatos. ${ }^{93}$

\section{Especial referencia a los comités de sanciones y grupos de trabajo del Consejo}

Este posible solapamiento en el ejercicio de las funciones asignadas, bien entre ellos, bien con otros órganos y entidades de Naciones Unidas es, especialmente, predicable de los comités de sanciones, los grupos de expertos que les asisten ${ }^{94}$ y los grupos de trabajo del Consejo. Así, por ejemplo, el Comité Especial sobre Operaciones de Mantenimiento de la Paz y el Grupo de Trabajo oficioso sobre cuestiones generales relacionadas con las sanciones mantienen debates sobre temas también abordados por el Comité Especial de la Carta de las Naciones Unidas y del Fortale-

90 Doc. A/59/47, anexo II, parágrafo 18, p. 11.

91 Resolución 60/1 de la Asamblea General del 16 de septiembre de 2005, parágrafo $163(\mathrm{~b})$.

92 Solicitada esta labor de asesoramiento en el Documento Final de la Cumbre Mundial 2005 (Doc. A/RES/60/1, parágrafo 163 (b), in fine), el informe fue presentado como Doc. A/60/733 del 30 de marzo de 2006.

93 Este Comité fue establecido por el Consejo de Seguridad en la Nota de su presidente S/2006/354 del 31 de mayo, acordándose que fuera copresidido por Estados Unidos de América y Eslovaquia durante el proceso. No obstante, durante 2007, su Presidencia sería ejercida por Eslovaquia y Sudáfrica (Doc. S/2007/20, p. 3).

94 Sobre estos grupos de expertos o "mecanismos complementarios para la gestión de las sanciones", véase Andrés Sáez de Santamaría, Paz, "Derecho, moral y eficacia en la práctica de las sanciones del Consejo de Seguridad", en Rodríguez Carrión, Alejandro J. y Pérez Vera, Elisa (coords.), Soberanía del Estado y derecho internacional. Homenaje al profesor Juan Antonio Carrillo Salcedo, Sevilla, Servicios de Publicaciones de Sevilla, Córdoba y Málaga, t. I, 2005, pp. 172-176. 
cimiento del papel de la Organización. Circunstancia que puede encontrar su origen tanto en una concepción aislada y no interconectada de los respectivos mandatos, como en la sobrecarga de trabajo de las delegaciones que lleva, entre otros extremos, a que los representantes permanentes no participen en ellos, salvo cuando les corresponde su presidencia. ${ }^{95}$

Ante ello, se ha solicitado la instauración de un mecanismo de evaluación de las prácticas, procedimientos y eficacia de las medidas del Consejo de Seguridad. Mecanismo que, para algunos, debería venir constituido por un nuevo órgano subsidiario que analizara el grado de aplicación de las medidas adoptadas y las mejores prácticas en ese sentido ${ }^{96} \mathrm{y}$, para otros, podría alcanzarse con la reunión periódica de los presidentes de los distintos órganos subsidiarios del Consejo de Seguridad, enriquecidas, en su caso, con la aportación de la Secretaría y de expertos externos. ${ }^{97}$ Expertos que están desempeñando una importante función en el eficaz desarrollo de la acción del Consejo de Seguridad, pero para cuya incorporación se solicita una cierta contención, dado que su naturaleza técnica no tiene por qué ser en todo caso apropiada para el Consejo y se han detectado casos de distorsión en la ejecución de sus mandatos, tales

95 Desde 2004, los miembros no permanentes suelen asumir dos presidencias de los dieciocho comités de sanciones y grupos de trabajo que existen, siendo sus excepciones en la actualidad: Japón y Grecia, con tres de ellas, y Congo, Eslovaquia, Ghana, Qatar y Tanzania, con una de ellas (estos órganos, sus presidencias y vicepresidencias para 2006 pueden consultarse en Doc. S/2006/66 del 31 de enero). Las delegaciones que no ocupan la Presidencia suelen estar representadas por sus consejeros o primeros secretarios (Doc. S/2004/135, p. 10). De acuerdo con el parágrafo 4 b) de la Nota presidencial Doc. S/ 1998/1016 del 30 de octubre, la mesa es elegida por cada Comité, sin embargo, los presidentes son designados, en la práctica, por los miembros permanentes que, a cambio, no suelen ocupar las mismas. La excepción viene representada por el Grupo de Trabajo sobre los niños y los conflictos armados, establecido en virtud del parágrafo 8 de la Resolución 1612 (2005) del 26 de julio, y presidido por Francia desde su creación (Doc. S/2005/659 del 20 de octubre). La delegación panameña recientemente ha solicitado que la Presidencia del Consejo de Seguridad sólo sea asumida por miembros no permanentes en lo que es una extensión de esta medida (véase intervención de Panamá ante el Grupo de Trabajo de la Asamblea General del 8 de febrero de 2007, p. 2, disponible en http://www.reformtheun.org/index.php).

96 Borrador de resolución del S5, anexo, parágrafo 6.

97 Propuesta de Filipinas durante su exposición como presidente de dos órganos subsidiarios (Doc. S/PV.5332 del 19 de diciembre de 2005, pp. 6 y 7). 
como la extralimitación en sus funciones o cierta ligereza en sus afirmaciones, efectuadas sin el respaldo de pruebas fehacientes. ${ }^{98}$

La preparación de ese catálogo de prácticas y procedimientos podría verse facilitada si fuese encomendada al Grupo de Trabajo Ad Hoc relativo a la documentación del Consejo de Seguridad y otras cuestiones de procedimiento ${ }^{99}$ que, sobre la base de la información previamente recopilada y transmitida por los distintos órganos subsidiarios, ${ }^{100}$ fomentaría la adopción por el Consejo de Seguridad de reglamentos marco por categorías de órganos subsidiarios, sin perjuicio de que algunas reglas generales pudiesen ser incorporadas a las Reglas de Procedimiento del Consejo. ${ }^{101}$ Ello facilitaría el establecimiento de mecanismos de coordinación y

98 La preocupación por la falta de rigor en las conclusiones motivó, incluso, la creación por la Secretaría de un equipo de trabajo interdepartamental encargado de elaborar directrices internas de funcionamiento entre las que se encontraban las que exigían el manejo de diversas fuentes y la utilización de las mejores fuentes probatorias (véase Doc. S/2004/135, pp. 12 y 13, y Doc. S/2005/228, pp. 7, 10 y 11.

99 Establecido en 1993, puede ser reunido en cualquier momento por su presidente, que durante el periodo febrero-junio 2006 es Japón. Concluida esta presidencia, se decidirá si se vuelve a la práctica habitual de la rotación mensual seguida en el órgano principal, si se mantiene el mandato de seis meses o si se convierte en anual como el resto de grupos de trabajo (Doc. S/2006/66, parágrafo 3).

100 Prácticamente, todos los comités de sanciones cuentan con unas directrices o reglas sobre sus métodos de trabajo que responden a un esquema similar, si bien son aprobados de forma autónoma por cada uno de ellos (se encuentran disponibles en sus correspondientes páginas web a las que se puede acceder desde $h t t p: / / w w w . u n . o r g / D o c s / s c)$. Por otra parte, empiezan a haber desarrollos en cuanto a la recopilación de las mejores prácticas. Así, el Comité contra el Terrorismo, establecido en virtud de la Resolución 1373 (2001) del 28 de septiembre, fomentó que en marzo de 2003 diversas organizaciones internacionales con competencia en la lucha contra el terrorismo compartiesen con los Estados miembros sus códigos y buenas prácticas (véase http://www.un.org/ sc/ctc/bestpractices.shtml). Por ende, la Subdivisión de Órganos Subsidiarios del Consejo de Seguridad de la División de Asuntos del Consejo de Seguridad del Departamento de Asuntos cuenta con varias bases de datos interrelacionadas, entre las que se hallan bases de datos para la programación de las reuniones de los comités y el seguimiento de las comunicaciones de éstos, aunque se ha puesto de manifiesto que su confidencialidad entorpece su utilización por los funcionarios, pues no están siempre abiertas a los mismos, y no tienen éstos una idea clara de su existencia y contenido (Doc. E/AC.51/2007/2/Add.2, p. 13).

101 Japón ha expresado su intención de trabajar con miembros y no miembros del Consejo de Seguridad, para hacer éste más transparente e incluyente a través de la mejora de sus métodos de trabajo, incluidos los de sus órganos subsidiarios (Doc. S/PV.5375 del 21 de febrero de 2006, p. 14). 
su funcionamiento coherente, tanto en su vertiente interna donde ya existen avances, ${ }^{102}$ como en la externa, referida principalmente a las organizaciones regionales. ${ }^{103}$ Además, se estaría contribuyendo a la petición de racionalización en el establecimiento y continuidad de los órganos subsidiarios y mecanismos de apoyo, ${ }^{104}$ pues no habría de crearse un nuevo órgano para trabajar en este objetivo y de su estudio podrían derivarse recomendaciones de fusión o reestructuración de los órganos existentes en función de los solapamientos detectados.

Estos reglamentos deberían contemplar asimismo reglas comunes de participación de los Estados no miembros en comités y grupos de trabajo, una de las peticiones de mayor abolengo en este proceso, con especial mención a los Estados destinatarios de estas sanciones y a los especialmente afectados, y que, en algún caso, se ha visto matizada con la precisión de que los invitados sean, además, expertos relevantes en la cuestión. Medidas que, existiendo en cierto grado en la práctica, deberían ver garantizadas su continuidad y ampliado su alcance. ${ }^{105}$ Un buen paso en

102 Véase en términos no determinados los informes del Grupo de Trabajo Oficioso del Consejo de Seguridad sobre Cuestiones Generales relativas a las Sanciones, Doc. S/2004/979 del 21 de diciembre, pp. 4 y 5, y Doc. S/2005/842, parágrafo 13, p. 6; y en las correspondientes Notas presidenciales, Doc. S/2004/1014 del 23 de diciembre, y Doc. $\mathrm{S} / 2005 / 841$ del 29 de diciembre. Su ejemplificación más desarrollada se encuentra entre los comités establecidos por las resoluciones 1373 (2001) del 28 de septiembre, 1267 (1999) del 15 de octubre, y 1540 (2004) del 28 de abril, y en ella también participa el Grupo de Trabajo establecido en la Resolución 1566 (2004) del 8 de octubre. Véase las Declaraciones presidenciales Doc. S/PRST/2005/3 del 18 de enero; Doc. S/PRST/2005/ 16 del 25 de abril; y Doc. S/PRST/2005/34 del 20 de julio.

103 Así, por ejemplo, el Grupo de Trabajo Oficioso del Consejo de Seguridad sobre Cuestiones Generales relativas a las Sanciones tiene entre sus funciones estudiar la posibilidad de que los informes de aplicación sean presentados por las organizaciones regionales y no por sus Estados miembros (Notas presidenciales, Doc. S/2004/1014 y Doc. $\mathrm{S} / 2005 / 841$, anteriormente citadas).

104 Doc. A/59/47, anexo II, parágrafo 18, p. 11. Esta petición fue explícitamente compartida por el Reino Unido (Doc. A/60/PV.48, p. 22).

105 Éste sería el caso de la propuesta formulada en el Borrador de resolución del S5, anexo II, parágrafo 7. No obstante, en el mismo también se incluye la medida de que los presidentes, tanto del órgano principal como de los órganos subsidiarios, habiliten vías informales de realizar aportaciones a su trabajo para los no miembros del Consejo (parágrafo 9). La apertura a los Estados destinatarios y especialmente afectados es solicitada en Doc. A/59/47, anexo II, parágrafos 16 y 17, p. 10. El acceso y la participación en ellos, en términos generales, también son reclamados por Alemania, Brasil e India (Doc. A/60/L.46, parágrafo 8 c)). 
esta última dirección ha sido asumido por el Comité establecido por la Resolución 1566 (2004), a través de la celebración de una reunión oficiosa con todos los Estados que estuvieran interesados y de la promoción de la presentación por escrito de sugerencias de éstos para asegurar la realización de su mandato. ${ }^{106}$ Estas consideraciones nos evocan otras medidas como la ampliación de la composición de los comités de sanciones para dar entrada a los Estados no miembros del Consejo ${ }^{107}$ que, además, serviría para aligerar la carga de trabajo de los miembros del Consejo y para superar los problemas derivados de la finalización de los mandatos de los miembros no permanentes antes de la conclusión del suyo en los correspondientes comités o grupos de trabajo (algo que podría conseguirse a través de una suerte de membresía ad hoc). ${ }^{108}$ Sin embargo, su viabilidad a corto plazo se presenta escasa.

Evidentemente, el suministro de información sobre el origen y causa de la acción de estos órganos subsidiarios y las evoluciones experimentadas por la misma es una fuente de implicación responsable y eficaz en su correcta puesta en práctica. Consciente de ello, el Consejo de Seguridad ya ha adoptado algunas medidas en este sentido, como por ejemplo, la presentación de informes de los presidentes de todos los comités de sanciones y grupos de trabajo en sesiones informativas formales públicas, ${ }^{109}$ a las cuales se ha de sumar la celebración de seminarios o talleres por algunos de sus miembros para incrementar su conocimiento y capacidad para aplicar las medidas adoptadas por el órgano principal y asegurar su cumplimiento, ${ }^{110}$ así como la más reciente invitación a sus presidentes o persona que ellos designen a celebrar reuniones informativas oficiosas, “cuando proceda", publicándose sus detalles de celebración en el Diario

106 Véase su informe contenido en Doc. S/2005/789 del 16 de diciembre, pp. 3 y 4.

107 Doc. A/59/47, anexo II, parágrafo 18, p. 11.

108 El Grupo de Trabajo Oficioso del Consejo de Seguridad sobre Cuestiones Generales relativas a las Sanciones, establecido por la Nota presidencial Doc. S/2000/319 del 17 de abril, ha sido quizá uno de los ejemplos más significativos de este problema, por lo demás presente en todos los demás.

109 Nota presidencial, Doc. S/1996/54 del 24 de enero. La última ha sido la celebrada el 20 de diciembre de 2006 (Doc. S/PV.5601 de igual fecha).

110 Como el celebrado en septiembre de 2005 por Argentina, con el patrocinio del Reino Unido, sobre "Promoción de la aplicación de la Resolución 1540 (2004) del Consejo de Seguridad", para todos los Estados del grupo regional latinoamericano-caribeño (véase Doc. S/2005/647 del 13 de octubre). 
de las Naciones Unidas. ${ }^{11}$ Sin embargo, algunas de las medidas ya adoptadas continúan presentando problemas en su ejecución, como es el caso de la presentación de los informes oficiales u oficiosos de los comités de sanciones que, en ocasiones, son distribuidos entre los Estados miembros después de ser comunicados a la prensa, o de las insuficiencias en la redacción de sus actas sumarias. ${ }^{112}$

Por último, es significativo de la preocupación gubernamental al respecto el carácter fugaz que ha tenido la petición de procedimientos justos y claros para la inclusión de personas y entidades en las listas de sanciones (y su revisión), propuesta por el Grupo de Alto Nivel sobre las amenazas, los desafíos y el cambio, ${ }^{113}$ y dirigida al Consejo por los representantes gubernamentales en la Cumbre Mundial 2005, ${ }^{114}$ por el momento, sólo ha sido recibida en el proyecto de resolución del S5 y sólo ha sido expresamente mencionada por dos de sus patrocinadores en estos debates. ${ }^{115}$ Sin embargo, la misma sí ha aparecido en los debates mantenidos en el marco del propio Consejo de Seguridad. ${ }^{116}$

111 Doc. S/2006/507, parágrafo 5. En esta línea ha de tenerse en cuenta el acuerdo de los miembros del Consejo de Seguridad por el que "alientan" a los presidentes de los órganos subsidiarios a difundir sus calendarios de reuniones, "cuando proceda", a través de sus páginas de Internet y el Diario de Naciones Unidas (Ibidem, parágrafo 47).

112 Ambas medidas adoptadas ya en la Nota presidencial, Doc. S/1999/92 del 29 de enero, parágrafos 18 y 19, reclamadas en Doc. A/AC.247/2003/CRP.3 (revisado) del 24 de abril de 2003, epígrafe III.A, parágrafos a) y c), en Doc. A/57/47 del 3 de julio de 2003, p. 64, y reiteradas por el S5 (Borrador de resolución, anexo, parágrafos 8 y 12, p. 3).

113 Doc. A/59/565, parágrafos 152, 180 b) y 182, pp. 52, 57 y 58. Recogida por Luck, E., op. cit., nota 24, p. 8; y Suiza, en su documento de trabajo no revisado, no sobrevivió a la concertación multilateral del S5.

114 Doc. A/RES/60/1, parágrafo 109.

115 Doc. A/60/L.49, parágrafo 12. Véase Singapur (Doc. A/61/PV.73 del 11 de diciembre de 2006, p. 24), y Suiza (Doc.A/60/PV.94 del 20 de julio de 2006, pp. 7 y 8 , Doc. A/61/PV.72 del 11 de diciembre de 2006, p. 18).

116 Así, los miembros del Grupo de Trabajo Oficioso sobre Cuestiones Generales relativas a las Sanciones han incorporado esa sugerencia, enriquecida con diversas proposiciones más, a las prácticas recomendadas al Consejo de Seguridad, adoptadas en diciembre de 2006 (Doc. S/2006/997 del 22 de diciembre de 2006). Asimismo, sobre estas listas y la necesidad de mejora en su elaboración y actualización, se debatió en el seno del Grupo de Trabajo del curso práctico "Eficacia inmediata” (Doc. S/2007/137, pp. 9-11). 


\section{Las reuniones del Consejo de Seguridad como elemento de apertura y transparencia.}

Junto con las medidas y formas de actuación del Consejo de Seguridad expuestas en los epígrafes anteriores, las reuniones del Consejo de Seguridad y la participación en las mismas constituyen elementos principales en la instauración de un nuevo espíritu en el órgano restringido que consiga que la diplomacia secreta ceda el paso en todo lo posible a la acción clara y ampliamente compartida. Quizá en el intento de explotar al máximo sus posibilidades en este sentido, las reuniones mantenidas por el Consejo de Seguridad han incrementado considerablemente sus modalidades, pudiendo hablarse en la actualidad de reunión formal, debate abierto, debate temático o de orientación, reunión abierta, sesión informativa abierta, reuniones privadas cerradas, reuniones privadas abiertas, consultas oficiosas de la totalidad, reuniones de la Fórmula Arria, reunión de miembros del Consejo, consultas con los países que contribuyen con tropas... en función de distintas variables entre las que se encuentra el interlocutor que a ellas se refiera. ${ }^{117}$ Un abanico que pudiendo llegar a provocar cierta confusión, sigue respondiendo en su esencia a la diferenciación entre reuniones formales (públicas o privadas) e informales, también conocidas como consultas oficiosas (sean plenarias, multilaterales o bilaterales).

El hecho de que en los últimos tiempos se haya primado la celebración de reuniones formales, sobre todo públicas, ${ }^{118}$ ha sido evidentemente un avance, pero ello no significa que sea suficiente. Así, por ejemplo,

117 Singapur elaboró un glosario sobre ellas (véase en http://www.mfa.gov.sg/unsc/ unsc_glossary.html). Los factores tenidos en cuenta por esta delegación fueron el objetivo perseguido con la modalidad, la presidencia, los participantes, el lugar de celebración y la publicidad que reciben, no estando entre ellos el del nivel de los representantes de los miembros del órgano, que permitiría para algún autor distinguir entre las reuniones periódicas del artículo 28.2 de la Carta y lo que se podría denominar "reuniones de alto nivel". Véase Chemain, Régis, "Article 28", en Cot, Jean-Pierre et al., (dirs.), La Charte des Nations Unies. Commentaire article par article, 3a. ed., París, Económica, 2005, pp. 968-970.

118 Esta reversión empezó a ser promovida desde el propio Consejo de Seguridad con la adopción de la Declaración de su presidente, Doc. S/PRST/1994/81 del 16 de diciembre; en parte, consecuencia de la Carta del 9 de diciembre de 1994 presentada por Francia (Doc. A/49/667-S/1994/1279 del 22 de noviembre de 1994), donde se abogaba claramente por una mayor aplicación de la regla de procedimiento 48. 
los debates temáticos han tenido que ver mejorada su ejecución a través de la limitación del tiempo de las intervenciones (normalmente, cuatro-cinco minutos), dado el elevado número de peticiones de participación que suelen producirse y el carácter reiterativo de las mismas, y de la introducción de distintos criterios del orden de intervención (alfabético, aleatorio), para dejar atrás la distinción entre miembros y no miembros del Consejo que llevaba a intervenciones temporalmente ilimitadas de los miembros del Consejo en la sesión de la mañana, y limitadas de los no miembros en la sesión de la tarde. ${ }^{119}$ Sin embargo, estos cambios no han derivado en una sustancial mejoría del carácter representativo del Consejo puesto que no ha sido modificada la práctica de adoptar las correspondientes declaraciones presidenciales o resoluciones inmediatamente después de haber intervenido todos los oradores de la lista, ${ }^{120}$ aunque se afirme la voluntad del Consejo de celebrar más reuniones formales públicas en el momento inicial de tratamiento de los temas. ${ }^{121}$

Por ende, ello no ha motivado que las consultas oficiosas plenarias dejen de ser el foro predilecto de adopción material de recomendaciones o decisiones del Consejo de Seguridad, lo que agrega importancia a reclamación de aplicación a las mismas de los artículos 31 y 32 de la Carta. ${ }^{122}$ Propuesta clásica en este proceso que, perdiendo fuerza al no estar basada en la literalidad de estas disposiciones, tal y como demuestra su recepción por el órgano restringido, ${ }^{123}$ tiene en su contra la aparición de

119 Sobre estas últimas mejoras, véase Hulton, Susanne. C., "Council Working Methods and Procedure", en Malone, David M. (ed.), The UN Security Council. From the Cold War to the 21st Century, Boulder, Lynne Rienner Publishers, 2004, pp. 247 y 248.

120 La excepción en estos supuestos viene constituida por casos como la Resolución 1540 (2004) del 28 de abril, que fue objeto de un largo periodo de negociación entre los miembros del Consejo, primero, y entre éstos y el resto de los miembros, después (presentaron su texto a los grupos regionales, y se escuchó al Movimiento de los No Alineados). Además, unos días antes de su adopción se celebró un debate público, a solicitud de Estados no miembros del Consejo (Canadá, México, Nueva Zelanda, Sudáfrica, Suecia y Suiza), durante el cual algunos miembros no permanentes (Brasil, Pakistán) anunciaron su voto negativo o abstención en el caso de no introducir modificaciones al texto que, según ellos, finalmente consiguieron (véase Doc. S/PV.4950 y Doc. S/PV.4950 (Reanudación 1) del 22 de abril de 2004, y Doc. S/PV.4956 del 28 de abril de 2004).

121 Doc. S/2006/507, parágrafo 26.

122 Doc. A/59/47, anexo II, parágrafo 8, p. 8, Doc. A/59/L.68, parágrafo 7 d), y Doc. A/60/L.46, parágrafo 8 b).

123 El Consejo de Seguridad, respecto de estas consultas, señala que "podrá invitarse a participar en los debates, caso por caso", a cualquier miembro de Naciones Unidas, no 
restricciones, injustificadas para mayor pesar, a la vasta interpretación que hasta ahora recibían. ${ }^{124}$

Distorsiones endémicas en la participación que, en algunos supuestos, van en contra de lo decidido por el propio Consejo, como sería el caso de las consultas con los países contribuyentes a las operaciones de mantenimiento de la paz. Celebradas tanto a nivel informal como formal (en este caso, normalmente, privadas), han sido objeto de un esfuerzo de perfeccionamiento altamente reseñable por parte del Consejo de Seguridad, hasta el punto de superar las reclamaciones del resto de Estados miembros. ${ }^{125}$ Sin embargo, aún estando previstos los mecanismos para consultar a los países que aportan contingentes o realizan contribuciones especiales, financieras o logísticas, en momentos previos al establecimiento de la operación, ${ }^{126}$ así como en temas de extensión, terminación o cambios significativos en los mandatos de las operaciones de mantenimiento de la paz o desarrollos inesperados, ${ }^{127}$ inclusive aquellos que pudieran poner en peligro la seguridad del personal de estas operaciones de paz, ${ }^{128}$ su puesta en práctica no ha sido del todo ejemplar.

Puestas de manifiesto la insuficiencia de las reuniones privadas mantenidas al ser de carácter predominantemente técnico y la escasa capacidad de influencia que en la decisión final tenían los participantes que no eran miembros del Consejo, ${ }^{129}$ y dada la inactividad en la que durante cierto tiempo se sumió el Grupo de Trabajo oficioso del Consejo de Seguridad sobre las Operaciones de Mantenimiento de la Paz (instrumento

miembro del Consejo, a miembros de la Secretaría y otras personas (Doc. S/2006/507, parágrafo 35, b) ii) a.). Sobre las consecuencias de esa literalidad, véase mi trabajo en $o p$. cit., nota 4.

124 Véase la alocución de India (Doc. A/58/PV.30 del 14 de octubre de 2003, p. 2) y las cartas idénticas de fecha 28 de julio de 2005, presentadas por Azerbaiyán (Doc. A/59/885-S/2005/496 del 28 de julio de 2005), protagonista de la citada restricción.

125 Véase las propuestas en el Grupo de Trabajo de la Asamblea General Doc. A/AC.247/ 2003/CRP.3 (revisado) del 24 de abril de 2003, epígrafe E, parágrafos 9 b)-1), en Doc. A/57/47 del 3 de julio de 2003, pp. 56 y 57.

126 Declaración del presidente del Consejo de Seguridad, Doc. S/PRST/1996/13 del 28 de marzo, y Nota presidencial, S/2002/964 del 27 de agosto.

127 Declaración presidencial, Doc. S/PRST/1994/62 del 4 de noviembre.

128 Resolución 1327 (2000) del 13 de noviembre; Declaración de su presidente, Doc. S/PRST/2001/3 del 31 de enero; y en la Nota presidencial, Doc. S/2001/905 del 25 de septiembre, parágrafo 10 .

129 Carta del 5 de febrero de 2004, presentada por Alemania, Brasil, Canadá, Egipto, Ghana, India, Japón, México, Pakistán y Sudáfrica, Doc. S/2004/99 del 5 de febrero. 
llamado a convertirse en el principal conducto de interacción con el Consejo de los países contribuyentes), ${ }^{130}$ el Consejo de Seguridad confirmó la necesidad de reforzar la relación con los países que contribuyen con tropas y con otros contribuyentes, aunque las opiniones de éstos últimos sólo serían tenidas en cuenta en los casos apropiados, lo que se resolvería "caso por caso y reunión por reunión". ${ }^{131}$ Con ello, vino a entorpecer la efectiva puesta en práctica por su Grupo Oficioso ${ }^{132}$ acerca de la medida de invitar a sus reuniones a los cinco principales contribuyentes de tropas, a los cinco principales contribuyentes financieros (teniendo en cuenta, en este caso, la importancia de cada país en cada misión), así como a otros países en función del tema u operación que se tratase. Una medida que suponiendo la objetivación de la participación desde márgenes flexibles y una mayor representatividad de las decisiones surgidas de esas consultas y reuniones, no ha sido recogida en toda su extensión y contenido por las últimas proposiciones formales de reforma al haberse limitado éstas a la reclamación genérica de la celebración periódica y oportuna

130 Este Grupo fue establecido en virtud de la declaración presidencial, Doc. S/PRST/2001/3 del 31 de enero, y cuyo mandato cubre las funciones de consolidación de la paz (Declaración presidencial, Doc. S/PRST/2001/5 del 20 de febrero), sin que la creación de la Comisión de Consolidación de la Paz haya supuesto, por el momento, variación alguna en este extremo. La instauración y descripción de este mecanismo de consultas se hallan en la Nota presidencial, Doc. S/2002/56 del 14 de enero, y el respaldo del Consejo a su función de foro participativo en Doc. S/2006/507, parágrafo 48. Por lo que respecta al órgano principal, las solicitudes de participación en reuniones formales públicas (Resolución 1353 (2001) del 13 de junio, anexo II.A), y privadas deberán formularse por escrito (Nota presidencial, Doc. S/2002/964 del 27 de agosto).

131 Doc. S/PRST/2004/16 del 17 de mayo, y Doc. S/2004/1040, p. 11. Esta diferencia en la participación otorga mayor importancia a las comunicaciones de baja y alta en la condición de contribuyentes con tropas (véase la incorporación de la India a la lista de países que aceptaron aportar personal militar a la Fuerza de las Naciones Unidas de Observación de la Separación, al reemplazar el componente saliente de Canadá, Documentos $\mathrm{S} / 2006 / 100$ y S/2006/101, ambos de 14 de febrero).

132 Reactivado, en 2004, al celebrar cuatro reuniones en las que participaron contribuyentes con tropas, financiamientos y otros Estados interesados en la operación de mantenimiento de la paz de Burundi (Doc. S/2004/1040 del 30 de diciembre, pp. 3 y 5). En 2005, se reiteró la petición de reactivación de su labor (Doc. A/59/47, anexo II, parágrafo 15, p. 10), que fue respondida con el mandato a su presidente de realizar la misión de determinación de los hechos sobre las dificultades de la Misión de Naciones Unidas en Etiopía y Eritrea, debidas a las restricciones de movimiento aplicadas a la misma (Doc. S/2005/694 del 2 de noviembre, y Doc. S/2005/723 del 17 de noviembre). 
de estas consultas, o de su mejora, contemplándose, eso sí, la necesidad de invitar a los Estados directamente afectados o interesados. ${ }^{133}$

Ante ello, no resulta extraño que tampoco hayan tenido eco aquellas sugerencias que explícitamente apostaban por una mayor participación en la adopción de decisiones, como eran las conectadas con el artículo 44 de la Carta. ${ }^{134}$ Un artículo que, ligado expresamente a las decisiones sobre el uso de la fuerza y a la celebración de los convenios especiales del artículo 43, encuentra en la ausencia de éstos uno de sus principales inconvenientes para ser puesto en práctica, ${ }^{135}$ sin que se esté aprovechando suficientemente la oportunidad que brinda este proceso para reclamar su celebración y el pleno desarrollo del capítulo VII de la Carta. ${ }^{136}$

133 Doc. A/60/L.46, parágrafo 8 f) y borrador de resolución del S5, anexo, parágrafo 16. Éste último sólo referido a los contribuyentes con tropas y a la mejora de las consultas, en caso de riesgo para la seguridad del personal, aunque la redacción inicial del documento de trabajo no revisado de Suiza (recomendación 9) era más parecida a la presentada por los candidatos a los asientos permanentes.

134 Sería el caso de la recomendación correspondiente del Grupo de Alto Nivel sobre las amenazas, los desafíos y el cambio (Doc. A/59/565, parágrafo 258, p. 77) y Luck, Edward, op. cit., nota 24, p. 8. En el Grupo de Trabajo de la Asamblea General, la sugerencia apuntaba a la mayor participación de los contribuyentes con tropas al proceso de adopción de decisiones, sin mayor abundamiento, en lo que abre también la posibilidad de un posible apoyo en el artículo 106 de la Carta (Doc. A/59/47, anexo II, parágrafo 8, p. 8).

135 Para M. F. Furet, ambos artículos "forment un tout imposible à dissocier" que diferencia claramente entre las fuerzas operacionales para llevar a cabo una acción militar y las operaciones de mantenimiento de la paz. Furet, Marie Françoise, "Article 44", en Cot, Jean-Pierre et al. (dirs.), La Charte des Nations Unies. Commentaire article par article, 3a. ed., París, Económica, 2005, pp. 1269-1271, 1270 y 1271.

136 La aplicación de estos dos artículos al autorizar el uso de la fuerza es la única medida sobre la que no existe el consenso en el Grupo de Trabajo de la Asamblea General (Doc. A/AC.247/2003/CRP.3 (revisado) del 24 de abril de 2003, epígrafe II.E, parágrafo 9 a), en Doc. A/57/47 del 3 de julio de 2003, p. 56). La crítica a la falta de desarrollo de estas previsiones ha sido también realizada por Sanjosé Gil, Amparo, "Algunas reflexiones sobre el Informe del Grupo de Alto Nivel creado por el secretario general, y el futuro del sistema de seguridad colectiva de las Naciones Unidas”, REEI, núm. 9, 2005, p. 11. Por su parte, en cuanto a las consecuencias de esta dejación en la puesta en práctica del artículo 43 y relacionados, véase Cardona Llorens, Jorge, "La 'externalización-privatización' del uso de la fuerza por las Naciones Unidas", en Rodríguez Carrión, Alejandro J. y Pérez Vera, Elisa (coords.), Soberanía del Estado y derecho internacional. Homenaje al profesor Juan Antonio Carrillo Salcedo, Sevilla, Servicios de Publicaciones de Sevilla, Córdoba y Málaga, 2005, t. I, pp. 317-342. 
En otro orden de cosas, existen otros actores cuya participación es especialmente importante si se quiere que el Consejo de Seguridad disfrute de los caracteres que la comunidad internacional proclama como fundamentales y se erija en indiscutiblemente legítimo y eficaz. Nos estaríamos refiriendo a la sociedad civil. ${ }^{137}$ Ésta, prácticamente imprescindible en la correcta ejecución de una gran parte de la acción adoptada por el órgano restringido, ve materializada su participación a través de las consultas celebradas bajo la Fórmula Arria, vista la escasa utilización de la regla de procedimiento 39 y la falta de apoyo que tiene su posible incorporación institucional al Consejo. ${ }^{138}$ Atenazadas por la admonición de que cualquier intento de formalización traerá funestas consecuencias para el futuro de estas consultas, ${ }^{139}$ las proposiciones de mejoras se han visto circunscritas a su definición (principalmente, en aras de evitar su utilización para dar audiencia a representantes gubernamentales), ${ }^{140}$ a la mayor asistencia de representantes procedentes del Sur y a su más frecuente celebración. ${ }^{141}$ No obstante, la contención en su formulación no ha conseguido evitar que estas reuniones con la sociedad civil comiencen a verse superadas y vaciadas de contenido ante el desarrollo de vías más informales de comunicación, como son las reuniones que los componentes de las misiones del Consejo de Seguridad mantienen en el lugar de destino, principalmente del mundo en desarrollo, con las organizaciones

137 Véase, sobre ella, a Pérez-Prat Durbán, Luis, Sociedad civil y derecho internacional, Valencia, Tirant Lo blanch, 2004.

138 Véase Abad Castelos, Montserrat, "El pluralismo como puente hacia el multilateralismo. El informe del Grupo de Personas Eminentes encargado de examinar las relaciones entre Naciones Unidas y la sociedad civil de 2004", REEI, núm. 9, 2005, p. 13, disponible en http://www.reei.org/.

139 Véase la intervención, en este sentido, de Francia en Doc. S/PV.4993 del 22 de junio de 2004, p. 12. La necesidad de su informalidad, pero como consecuencia de ella, también la de informar sobre el procedimiento a seguir, y en cierta medida la de su planificación, se ha puesto de manifiesto en Doc. S/PV.5601, p. 13.

140 Doc. A/AC.247/2003/CRP.3 (revisado) del 24 de abril de 2003, epígrafe II.G, parágrafo 13, en Doc. A/57/47 del 3 de julio de 2003, p. 60. Sobre esta medida, no se había alcanzado aún el consenso.

141 Doc. A/58/817, parágrafos 97 y 98, p. 49. Véase también la intervención del director ejecutivo del Centro Europeo para la Prevención de Conflictos (Doc. S/PV.5264 del 20 de septiembre de 2005, p. 4). 
no gubernamentales y representantes varios de la sociedad civil, ${ }^{142}$ o el mantenimiento creciente de contactos, cerrados y selectivos, con el Grupo de Trabajo de las ONG sobre el Consejo de Seguridad, ${ }^{143}$ por no mencionar que se ha institucionalizado su perversa utilización.

Creadas para permitir los encuentros informales con la sociedad civil, en los últimos desarrollos realizados por el Grupo de Trabajo Oficioso sobre Documentación y Otras Cuestiones de Procedimiento se ha consagrado, en primer lugar, su destino al encuentro oficioso con Estados miembros (¿para qué si teóricamente ya van a poder participar en las consultas oficiosas?), organizaciones (¿acaso buscan los miembros del Consejo la interactividad que renuncian establecer en sus otras y más apropiadas reuniones, en las que sí participan o podrían participar esas organizaciones?) y personas pertinentes de una forma oficiosa (¿no está pensada para ellas las regla de procedimiento 39? Si no son personas de la sociedad civil, ¿quiénes son? Si son altos representantes o enviados especiales del secretario general, ¿para qué la Fórmula Arria? Si son ministros de Estados miembros, ¿es que aquéllos no representan a éstos?) y, en segundo lugar, el acuerdo en aras de "considerar" su utilización para los encuentros con los representantes de la sociedad civil y de organizaciones no gubernamentales. Eso sí, para que nadie proteste, se ha dado entrada a las nuevas tecnologías de la comunicación (videoconferencia) para poder contactar con las organizaciones no gubernamentales locales sugeridas por la Secretaría. ${ }^{144}$

\section{CONSIDERACIONES FINALES}

Situada la mejora de los métodos de trabajo del Consejo de Seguridad en un segundo plano formal, que no material, en el proceso de reforma del órgano restringido, cuando recibió el trato merecido a través de la

142 Sobre estas misiones, véase Novosseloff, Alexandra, "Les 'Missions Spéciales' du Conseil de Sécurité des Nations Unies”, AFDI, 2003, pp. 165-175, especialmente pp. $172-175$.

143 Con el tiempo, este Grupo ha ido consolidando la celebración de encuentros con miembros del Consejo, privadas y sin acta alguna, sobre temas o asuntos concretos, a las que acuden unos dieciocho a veinticinco representantes de los treinta que componen su Consejo de Dirección. Mayor información sobre el mismo puede encontrarse en http:// www.globalpolicy.org/security/ngowkgrp/index.htm.

144 Todo ello en Doc. S/2006/507, parágrafo 54. 
presentación de un proyecto de resolución exclusivamente sobre esta dimensión, ésta desplegó un cierto efecto cicatrizador de las heridas abiertas por la cara relativa a su composición y sistema de votación, mostrando a los Estados miembros que el entendimiento y el respaldo común eran posibles. No se debe menospreciar el hecho de que, tras su presentación, la férrea defensa de los intereses propios parece haber cedido el paso a los criterios de flexibilidad alrededor de las propuestas de ampliación del número de miembros y de ampliación de la titularidad del derecho de veto. Pero, ¿qué poseen estas cuestiones para que la sola presentación de su proyecto de resolución haya conseguido traer a los Estados miembros al redil de la negociación y al camino del consenso?

De por sí, esta cara de la reforma silenciosamente, sin severos enfrentamientos ni estridencias, ha generado que el propio Consejo de Seguridad, a su ritmo y placer, eso sí, haya incorporado mejoras a su procedimiento solicitadas por el resto de miembros. Sin embargo, siendo como son la principal vía para que el Consejo de Seguridad reúna los caracteres que la comunidad internacional proclama como fundamentales y se erija en indiscutiblemente legítimo y eficaz, la aprobación de una resolución de la Asamblea General en este sentido habría evidenciado este extremo y que la parte verdaderamente importante de la reforma estaba concluida, resaltando, en consecuencia, que la consecución de los objetivos marcados nunca ha dependido de asientos, sino de voluntades y modos de proceder.

Ahora que el final parece estar dibujándose en el horizonte, sólo queda pedir que las delegaciones tengan presente la importancia intrínseca que hemos visto tienen estas cuestiones y resistan la tentación de utilizar o eviten el uso de los métodos de trabajo para maniobras políticas de origen fraudulento o mero efecto compensatorio que pongan en peligro los logros ya alcanzados.

Sea por su poderosa trascendencia o por la gran evolución que estos temas han tenido a lo largo de los años, sea por el modo de trabajar adoptado en este proceso o porque su incorporación y ejecución no exige enmienda alguna de la Carta, si se avanza en la reforma como algunos esperanzados espíritus esperan, se impone que la Asamblea General adopte, bien dos resoluciones o bien una única con doble cuerpo, como ocurrió aquél otro significativo día de diciembre de 1963, diferenciando las cuestiones de composición y sistema de votación de las de procedimiento. En el texto correspondiente a éstas últimas habrán de recogerse, 
no la selección de la que han hecho gala los proyectos de resolución hasta ahora presentados, sino todos los aspectos de procedimiento tratados y desarrollos habidos a lo largo de este proceso en el grupo de materias II. Con ello, todos los miembros de la Organización harán saber a los miembros del Consejo de Seguridad de qué forma quieren que, en la práctica, éstos ejerzan las funciones asignadas por la Carta, cubriendo, asimismo, de legitimidad aquéllas medidas ya decididas por el órgano restringido. Y, cuando lo hagan, deberán ser consecuentes con sus reclamaciones de transparencia y representatividad y decirle al Consejo que la forma de mejorar su procedimiento no es a través de notas o declaraciones presidenciales, sino actualizando y aprobando la versión definitiva (no por ello inmutable) de sus Reglas de Procedimiento. Ello porque resulta innegable que el modo en que los órganos de la Organización desarrollan su función es trascendental para el futuro de la misma, pero también que no es suficiente con ser eficiente, transparente, representativo, democrático, legítimo y eficaz. También hay que parecerlo. De esta forma, tanto aquéllos que no poseen una buena memoria institucional en las condiciones actuales, como aquéllos que, en nombre de la flexibilidad en su dinámica de actuación, no cesan de fomentar el reinado de la arbitrariedad y la formulación de críticas no siempre justificadas, saldrán beneficiados porque, a la postre, de nada servirá a ninguno de ellos un órgano desacreditado, desprovisto de su halo legitimador e ineficaz. 